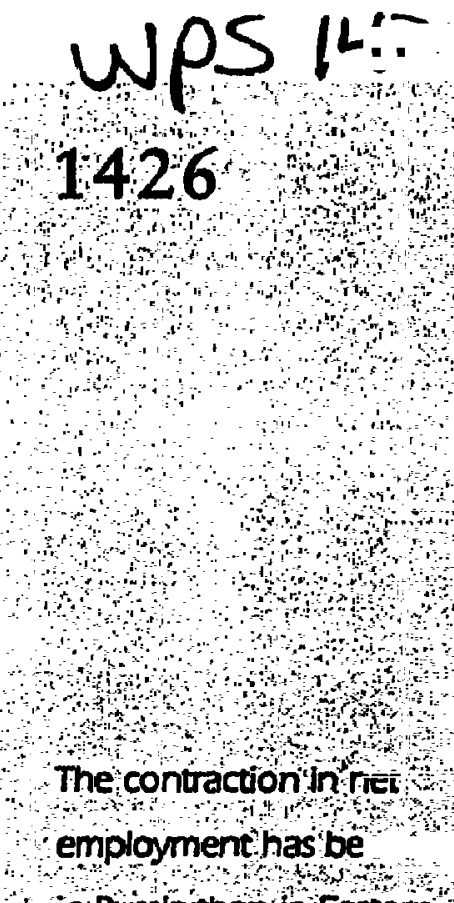

Russian Unemployment

\title{
Its Magnitude, Characteristics, and Regional Dimensions
}

Simon Commander

Ruslan Yemtsov

The World Bank

Economic Development Institute

National Economic Management Division

and

EDI Moscow Office

February 1995

in Russla than in Easiniti

Eürope, but:Russtan

unemployment has

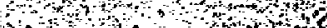

increasing and witrs increase funtier,

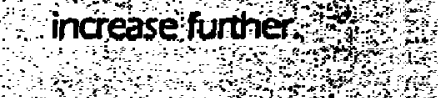

Policy Research Working Paper 


\section{Summary findings}

Registered unemployment in Russia is now 2 percent; surveys indicate a true rate of between 5 and 6 percent. Until now, flows in and out of unemployment have been quite large, with durations low.

This may be changing as the ease with which workers are matched to jobs declines - in part because of financing constraints on firms. Already there is great regional variation in unemployment - which, as this model indicates, is likely to persist because of the mismatch in distribution of jobs and the unemployed.

This paper is a joint product of the National Economic Management Division and the EDI Moscow Office, Economic Development Institute. The study was funded by the Bank's Research Support Budget under the research project "Labor Markets in Transitional Socialist Economies" (RPO 677-30). Copies of this paper are available free from the World Bank, $1818 \mathrm{H}$ Street NW, Washington, DC. 20433. Please contact Valerie Reid, room M3-107, extension 35195 (44 pages). February 1995. 


\title{
Russian unemployment: its magnitude, characteristics and regional dimensions
}

\author{
Simon Commander and Ruslan Yemtsov ${ }^{I}$
}

World Bank

${ }^{1}$ This paper is part of a continuing research program being done in conjunction with Andrei Tolstopiatenko and Oleg Zamkov, both of whom have made contributions to the paper. Thanks to Jeni Klugman for support, Irina Perova for providing data and to Tito Boeri, John McHale and Cecilia Ugaz for very valuable comments and help. 


\section{Introduction}

Unemployment, as measured by those registering at Employment Offices, has risen very gradually in Russia despite large order output losses and dislocations to trade. By mid-1994 registered unemployed was no larger than 2.1 percent of the labor force. At first inspection, this seems to tell a different story from experience in transitional economies in Eastern Europe. In the latter, adverse shocks fairly rapidly translated into major employment adjustments in the state sector. Initially these adjustments were carried out by voluntary means; only after some lag did involuntary separations begin to dominate. The obvious questions that then arise are whether these different employment to output elasticities accurately reflect a combination of differences in the macrceconomic environment -- particularly the flow of subsidies to firms -- institutional variation, as well as problems of measurement, both with respect to unemployment as also for output itself ? As we shall see, registrations data give a rather different - and lower -- level of unemployment than survey-based results, while output numbers are likely underestimated as they do not adequately capture the effects of the stock adjustment -- the growth in private activity in trade and services -- and associated structural changes taking place in the economy.

A further consideration that may explain this different evolution is the underlying preferences and constraints facing firms - in part contingent on outside factors but significantly related to inside control factors. Contrary to East European experience Russian firms have not operated as if governed ex ante by a hard budget constraint. Indeed, there are many reasons for thinking that employment, rather than, say, output, has been the main factor determining the size and distribution of subsidies. One result -- mixing both elements of benevolence and self-interest - has been the apparently widespread use of involuntary leave and short time work as firms continue to maintain some form of labor attachment with their initial stock of workers. In addition, firms have borrowed from workers through wage arrears in large magnitudes. Average lags in settlement of wage arrears have grown over time, hence imposing a large inflation tax on settlements.

The overall picture thus appears to be one in which firms and workers have traded wages against relative employment stability. Hours adjustment and lags in wage settlements have run alongside non-trivial gross flows but little change to net employment. The latter result can be 
traced to a combination of adjustment costs as well as expectations with respect to future output and hence likely constitutes some form of labor smoothing as well as benevolence. Even so none of these motivations can satisfactorily explain why so many state -- often now privatized -- firms continue to hire and report large hiring rates.

This paper is an attempt to sort out some of these apparent differences, first by getting a more appropriate measure of changes to employment and unemployment. We then look in some detail at the characteristics of the unemployed, drawing on a representative nationwide survey of unemployed individuals. Finally, we discuss an important - and hitherto neglected -- feature of unemployment; the regional dimension. We indicate some of the reasons for why the significant regional differences in unemployment that are now beginning to emerge may be long-lasting, in part because of the lack of labor mobility.

\subsection{Measurement}

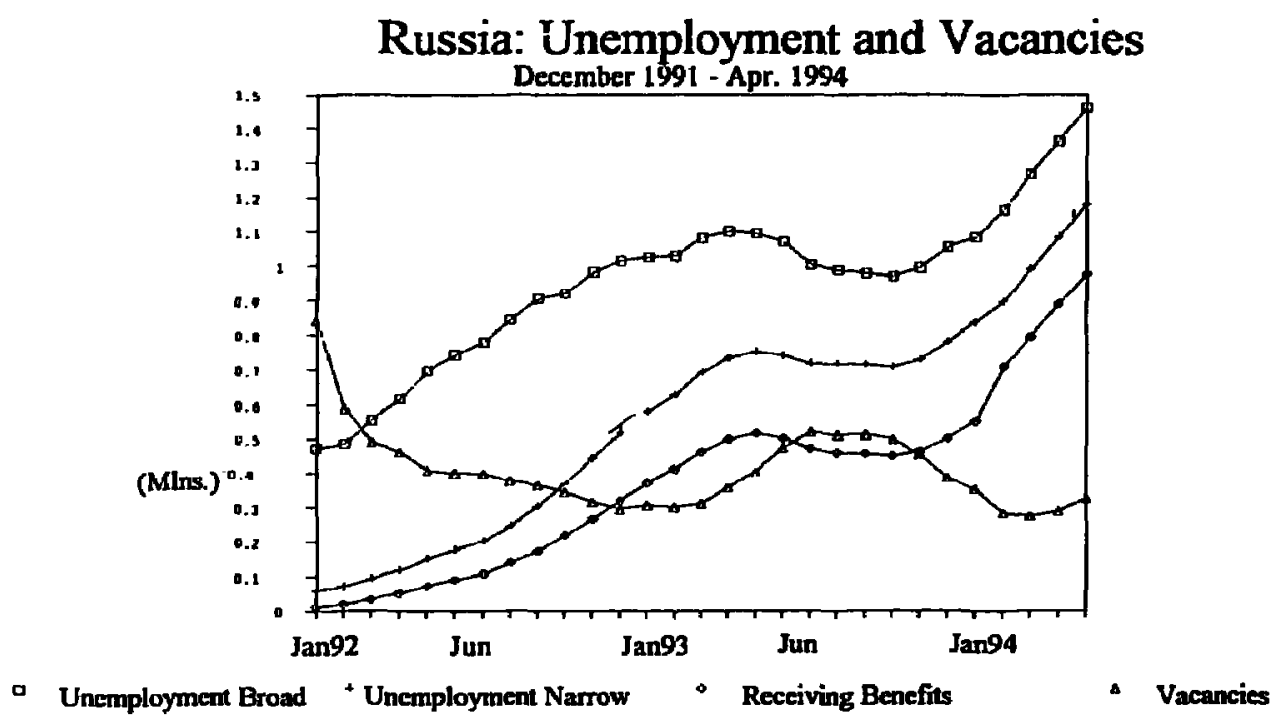

Figure 1

Registrations data appear to tell us that not only has unemployment risen gradually and episodically but that it remains a small number (Fig. 1). This appears to be consistent with the evolution of employment as given in Fig.2 which shows a huge asymmetry between adjustments to GDP, industrial output and employment since 1990. Further disaggregating the changes to employment and output in terms of regions tells us a similar story with one important addition; 
that there is significant regional diversity in the asymmetric nature of the changes, with most of the variation over regions entering through the change to output rather than employment (Fig.3).

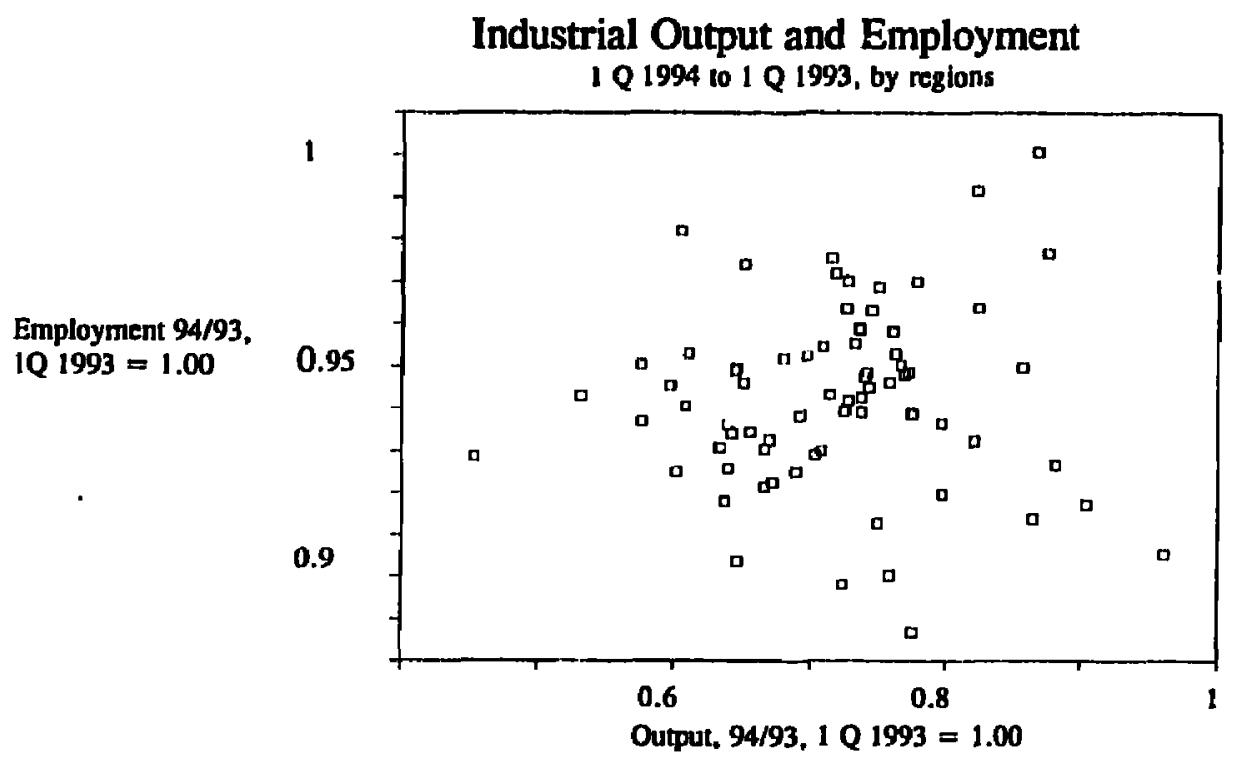

Figure 2

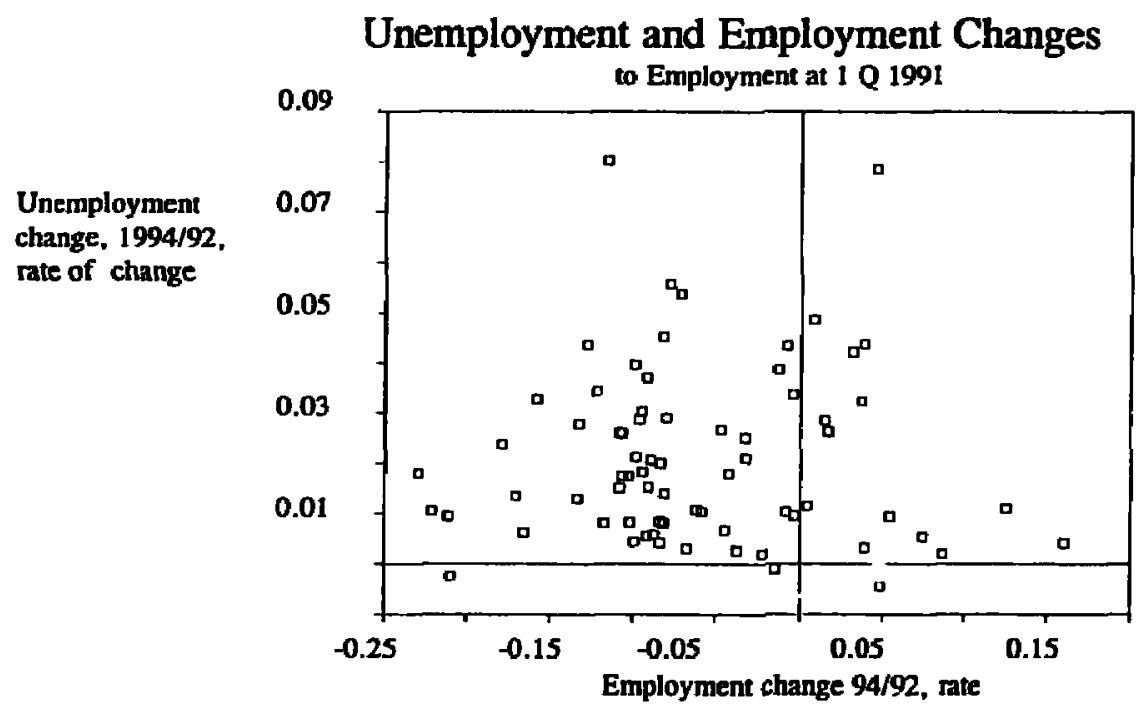

\section{Figure 3}

Unemployment stocks initially climbed sharply in the first year of reform, but actually declined through most of 1993 . Thereafter, there has been a further surge, resulting by mid-1994 in roughly 1.5 million workers being out of work with nearly one million in receipt of benefits. Vacancies have sharply tailed off and the ratio of vacancies to unemployment has fallen sharply since mid-1993. One argument explaining this recent evolution is to see acceleration as being 
associated with the lagged effects of the fiscal corrections and tighter monetary policy pursued in the latter part of 1993 and carried over into 1994. Taken this way, the presumption is that firms have increasingly been forced to separate labor as soft credits and other subsidies have been squeezed.

Table 1: Unemployment in Russia : Various Measures 1992-1994.1 (percent of labor force)

1992

1993

1994 (March/April)

Labor Force Survey

4.8

5.5

5.9

vCroM Survey

6.2

6.7

RLMS*

5.5

Registered Unemployed

1.1

1.4

2.1

Notes: Labor Force Survey 1992 and 1993 figures are mid-year; RLMS relates to August 1992; VClOM surveys relate to June 1993 and April 1994.

If we match up registrations with survey numbers, the apparent discrepancy is large, as can be seen in Table $1^{2}$. The gap is of the order of 4 percent of the labor force or around 3 million individuals. Note that the gap is almost stationary over the period 1992 to mid-1994. However, the Labor Force Survey numbers are not strictly comparable with OECD measures. Aside from the relatively infrequent applications of these surveys, the numbers do not satisfactorily discriminate over non-participants and the unemployed. Indeed, roughly $20 \%$ of the surveyed unemployed appear to be students and pensioners. However, it appears that, contrary to common assumption, Russia inherited a significant stock of unemployed from the Soviet period. Further, despite the size of shocks, the upward drift in the survey generated numbers is not particularly substantial. The main movement appears in the registration numbers which have gone from near zero to over 2 percent in just over two years.

Measurement is further complicated by the widespread and growing prevalence of hours adjustment as one response of firms to adverse shocks. Adjustment along the time dimension has

\footnotetext{
${ }^{2}$ The survey numbers come from respondents lacking work but available and searching.
} 
been important and in some sense a counter approach to outright labor shedding. One implication of course is that the productivity decline in Russian industry has been considerably smaller when factoring in time. Table 2 gives the evolution of short time and involuntary leave since 1992. Several features stand out. The numbers of workers facing hours adjustment is quite large and on a rising trend. By 1994.q1 over 14 percent of those employed in firms with more than 200 workers had either experienced an involuntary leave spell in that quarter or were subject to short time. Involuntary leave has dominated with average spells lengthening through 1993 . For the first quarter of 1994 the average spell was around a month.

Table 2: Russia -- Hours adjustment and regional range, 1993-1994

$$
\begin{array}{lllll}
1993 q 1 & 1993 q 2 & 1993 q 3 & 1993 q 4 & 1994 q 1
\end{array}
$$

Category

SHORT TIME (share of employed)

\begin{tabular}{lcclll} 
Russia & $1.7 \%$ & $1.6 \%$ & $1.9 \%$ & $2.8 \%$ & $5.9 \%$ \\
max & 10.1 & 8.0 & 8.2 & 9.0 & 13.5 \\
min & 0.1 & 0.1 & 0.1 & 0.1 & 0.2 \\
INVOLUNTARY LEAVE & (share of employed) & & & \\
Russia & $3.4 \%$ & $4.9 \%$ & $6.5 \%$ & $8.6 \%$ & $8.3 \%$ \\
max & 13.0 & 15.4 & 16.8 & 20.4 & 16.0 \\
min & 0.3 & 0.6 & 0.3 & 1.2 & 1.0 \\
AVERAGE DURATION OF INVOLUNTARY LEAVE (days) & \\
Russia & 18 & 18 & 24 & 29 & 19 \\
max & 49 & 47 & 63 & 64 & 45 \\
min & 5 & 9 & 10 & 15 & 4 \\
\hline
\end{tabular}

Source: Roskomstat Data

[Note: Dat2 are cumulative and cover firms with >200 employees] 
The prevalence of short time work and involuntary leave spells begs the question of what this signifies. Is this merely one manifestation of firms' unwillingness to separate workers involuntarily or is it part of a dynamic adjustment where de facto labor contracts are more flexible and allow firms to adapt to changes in relative demand ? Given the fact that Russian firms entered the transition with large labor hoarding, it seems at first inspection unlikely that the latter explanation is completely appropriate. Rather what we observe points to a clear employment bias, a bias that is likely to have been exacerbated by non-trivial adjustment costs.

Clarifying the nature of the hours adjustment that is observed has obvious implications for how we measure unemployment. For example, workers that remain in effect attached to firms with high probabilities of being put to work or shifting to full(er) working time should not be viewed as unemployed ${ }^{3}$. The survey evidence presented in Section 2 allows us to discriminate over a range of labor market states, including workers subject to some form of hours adjustment.

\subsection{Changes to employment}

We now attempt to get a better feel for the magnitudes by accounting for changes from the side of employment. Aggergate data indicate a net employment loss of around 4 percent or around 3 million jobs between 1991 and 1993. Much of this contraction has been concentrated in industry, which has accounted for 36 percent of the aggregate employment loss. Offsetting gains - largely in self-employment and private activities -- are necessarily imprecise numbers. Even so, putting the numbers together in this way also allows us to account partially for the change in state and private employment over this period. It is striking that the increase in private and selfemployment was roughly equal to the loss in employment in industry. What is clear, however, from the adding up is that the gap is closed by the change in unemployment and non-participation of the order of 2.7 million for end 1993 over 1991. How exactly this is distributed over nonparticipation and unemployment is still unclear.

Movements out of the labor force also appear to be large. Part of this can be construed as a level effect consistent with a lowering of participation rates from artificially high levels. In addition, it seems likely that job losses have been concentrated on early retirees and on workers more likely to leave the labor force, particularly women. Registrations data show that the initially

\footnotetext{
${ }^{3}$ Movement to shorter time work could be explained either in terms of the demand side or by labor supply responses of workers with preferences for shorter time working, possibly women and younger workers.
} 
high share of women -- c. 70 percent at mid-1992 -- has declined quite sharply over time. By early 1994 the share of women at just over 51 percent of the unemployed was roughly equal to their share in the total population. It seems likely that part of this decline can be attributed to movement out of the labor force. Experience in Eastern Europe clearly indicates the importance of non-participation in the early period of transition and it seems likely that later flows out of employment will be mostly absorbed by growth in unemployment.

Putting together the changes to employment and unemployment is, however, problematic and largely so for measurement reasons. Using regional observations for 79 oblasts, Fig.4 indicates very large disparities in these respective rates of change. The bulk of oblasts have experienced negative changes to employment significantly in excess of the change to unemployment. It appears that a 1 percent change in unemployment has been associated with a 2.5 percent change in emplcyment. The discrepancy can part be traced to shifts to nonparticipation, as well as non-registration, but also to coverage; the data on employment represent only firms with more than 200 employees. As most employment growth is occurring in small firms and/or self-employment, this likely accounts for a good part of the gap.

In short, there are clear measurement problems, particularly with respect to nonparticipation. Nevertheless, the clear impression is that unemployment in Russia is significantly higher than registered but that a significant proportion of this additional unemployment was a carry-over from the Soviet period and that it has been only weakly trended since the start of the reform period.

\subsection{Flows}

A feature of Russian unemployment appears to have been the size of the flows out of unemployment. Compared with the characteristic East European experience -- with low inflow rates to unemployment and yet smaller outflow rates -- Russian flows to unemployment have been relatively small, while outflows -- including outflows to jobs -- have been large in 1992 and 1993. We observe a clear shift upwards in the inflows rate in the first quarter of 1994 with the monthly rate approaching 0.5 percent. Fig. 4 also provides a range for regional inflow rates. This range is broad, a feature we return to later. Outflow rates -- Fig. 5 indicates -- are not only large, averaging over 15 percent per month since 1992, but have remained relatively stable. However, 
there is a mild decline in outflows to jobs in 1994.q1 but the rate remained in the range of 6-7 percent per month (Fig.6). And both for inflows and outflows, Fig. 7 points to large variation

\section{Regional Infow Rates to Unemployment: Range and Average}

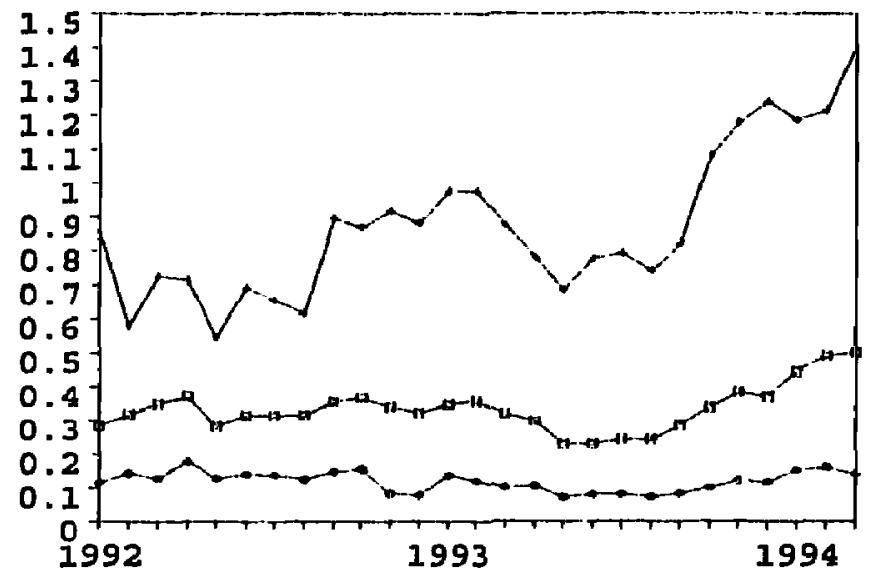

- Russia Inflow Ratef - Maximum Inflow rate " Minimum Inflow rate

Figure 4

Regional Outflow Rates from Unemployment: Range and Average

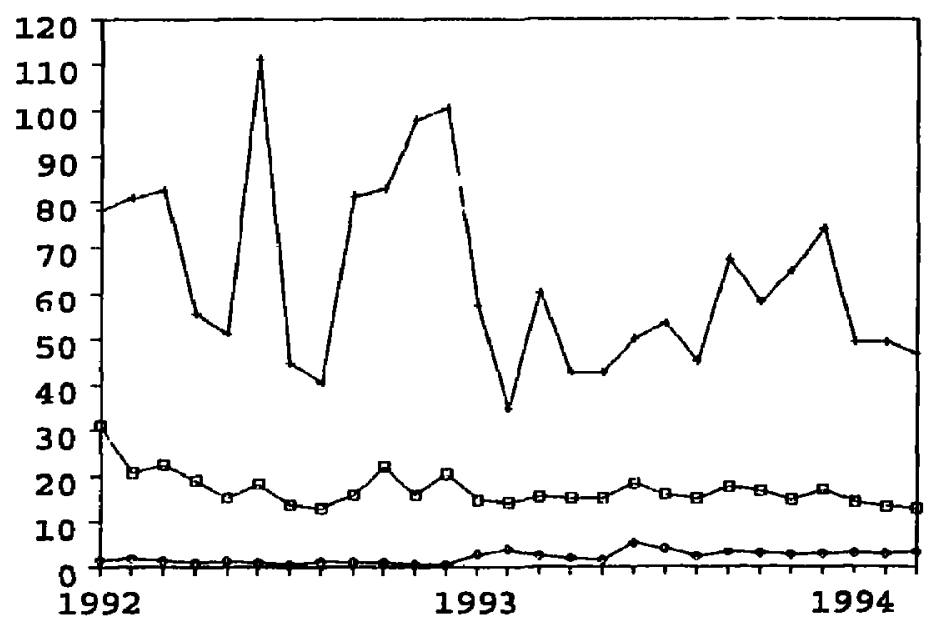

- Russia Outflow \& + Max Outflow rate, * * Min Outflow rate,

Figare 5 

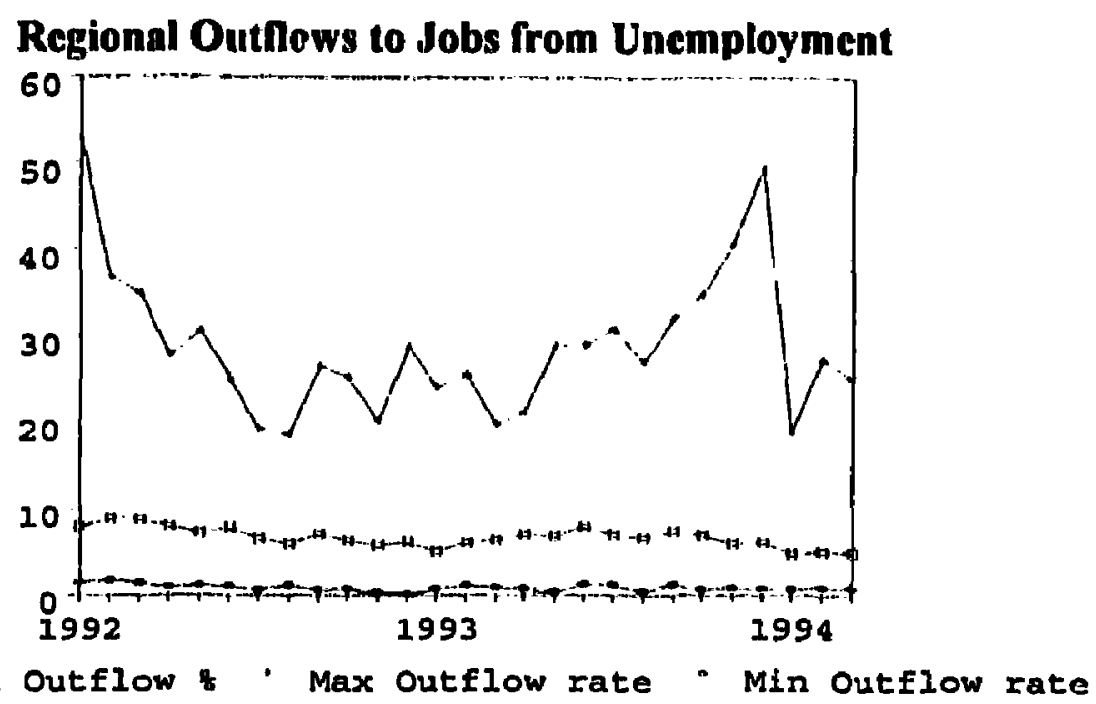

Figure 6

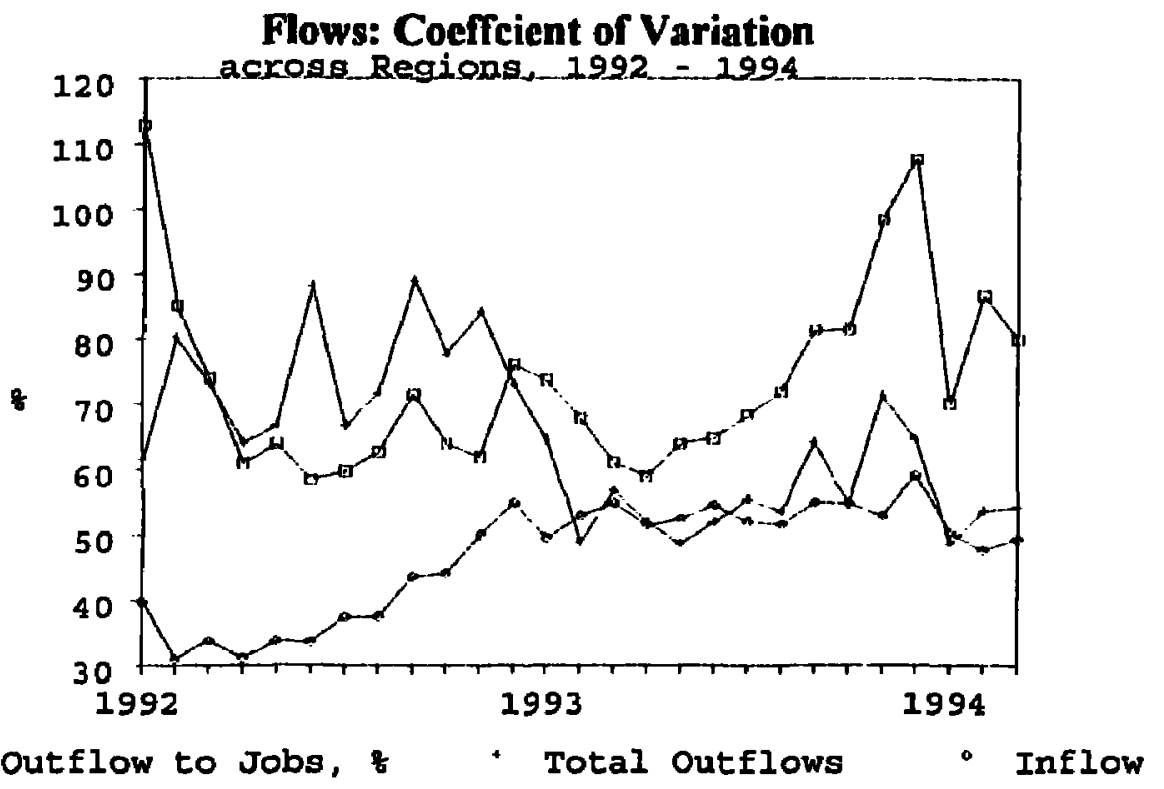

\section{Figure 7}

across regions over time. Clearly, we would like to know how much of the regional variation in unemployment can be attributed to inflows as against differences in outflow rates. We accordingly decompose variance of the regional unemployment growth rates into variances of inflows, outflows and covariance term. ${ }^{4}$ This decomposition shows that for the period 1992 -mid

${ }^{4}$ By definition, we have $\operatorname{ar}\left(u_{n+1}-u_{n}\right)=\operatorname{Var}\left(i_{n, s+1}\right)+\operatorname{Var}\left(o_{n, t+1}\right)-2 \operatorname{Cov}\left(i_{n, t+l}, o_{r, t+1}\right)$, where $u$ denotes unemployment rate of $r$ gion $r$ at the beginning of the period $t$ and at the end $t+1, \quad i$ and $o$ denote respectively 
1994 variance of inflows to registered unemployment across regions to the the total variance of unemployment growth is as high as $540 \%$ (compared to $444 \%$ in Bulgaria or $375 \%$ in Poland) ${ }^{5}$. At the same time variance of outflows from unemployment is lower, representing only $283 \%$ of the total variance of unemployment growth. This suggests that the differences in regional unemployment growth are driven largely by inflows. There is high covariance in movements to and out of the regional pools of unemployed. At the same time it is worth noting that inflows, while largely explaining regional discrepancies in unemployment are still very low relative to Eastern European comparators.

The low inflows rate has to be traced to the decisions of firms. Firms can pick redundancies as well as relying on attrition. In addition, workers can of course quit their jobs. An increase in separations will show up on the inflows side. What data are available, we have already indicated, suggest that separations' decisions by Russian firms have been rather small relative to the size of shocks to demand. Further, the distribution of separations over voluntary and involuntary components is somewhat surprising. Employment Offices have information providing partial coverage on flows to unemployment and their impulse and they show that lay-offs accounted for roughly 30 percent of registrations. However, Goskomstat figures covering total separations indicate that only 7-9\% of separations through 1992 and early 1993 were from layoffs. The clear impression -- supported by firm-level surveys ${ }^{6}$-- is that involuntary separations have remained small, amounting on average to no more than $25 \%$ of total separations in the firm sector. One implication is that a significant part of the flow to unemployment has to be traced to apparently voluntary decisions by workers; subject to an important caveat. That is, the boundary between quits and involuntary separations may not be watertight; some proportion of those quitting may indeed have little option. Even so, assuming that the voluntary component is still large, the aggregate data indicate that workers likely attach a high probability to exiting from unemployment; a fact seemingly born out by some survey results reported below.

inflows and outflews between $t$ and $t+l$ (all magnitudes are expressed as proportion of the average-period labor force).

${ }^{5}$ T.Boeri, S.Scarpetta "Convergence and Divergence of Regional Labour Market Dynamics in Central and Eastern Europe"/ Paper presented at Technical Workshop on Regional Unmeployment in Central and Eastern Europe, Vicnna, IHS, 3-5 November, 1994.

${ }^{6}$ As indicated in Commander, McHale and Yemtsov (1994) 
A further set of features that are important in understanding the evolution of the inflow rate are, first, the non-trivial shift of workers into non-participation and, second, the use of hours reduction by firms, hence avoiding any formal separation of workers.

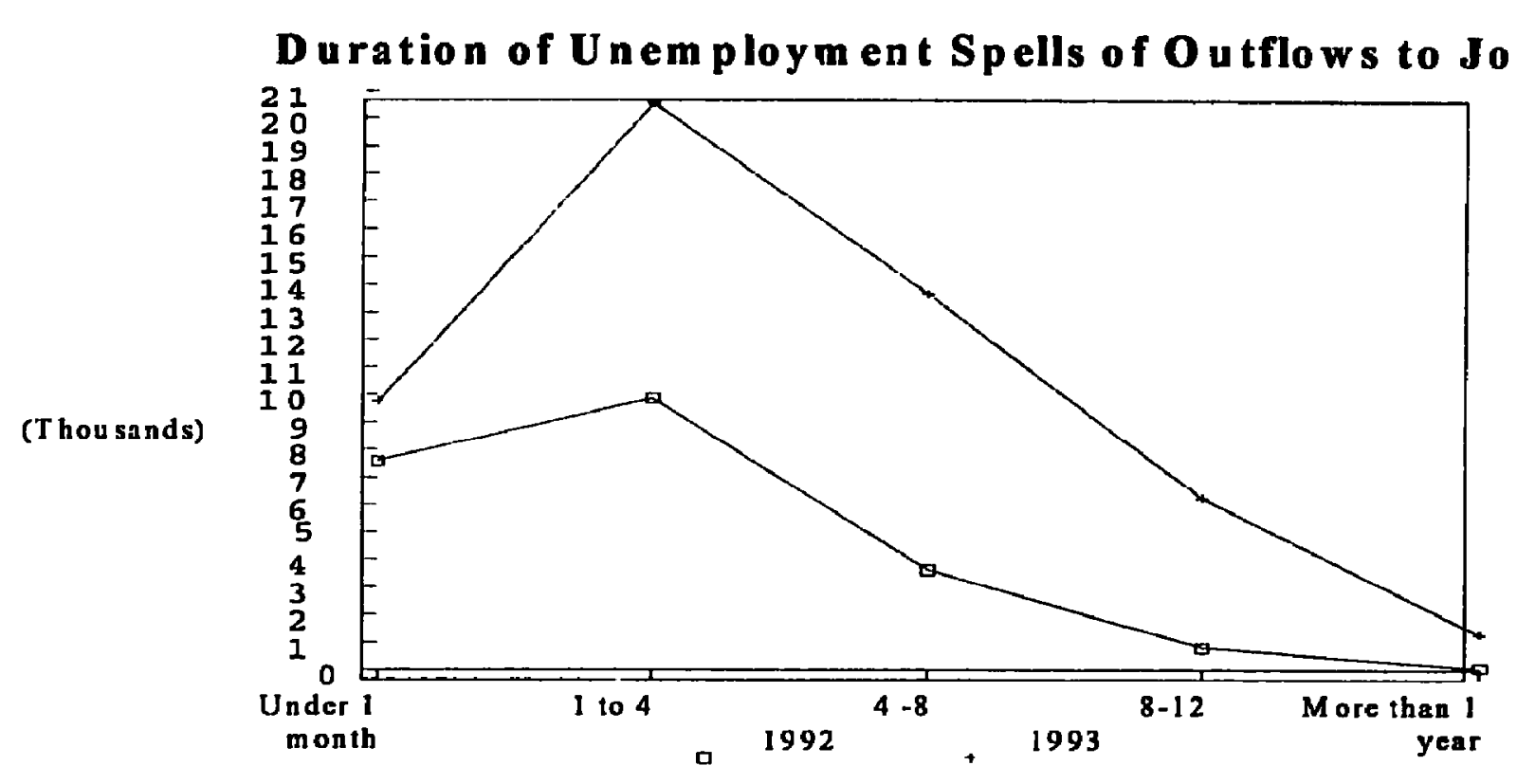

Figure 8

On the outflows side, official data suggest that through 1992 and 1993 flows to jobs remained not only large -- accounting for over $40 \%$ of total outflows - but were dominated by flows to state firms, albeit with increasing flows over time to service sector and other jobs outside of industry and agriculture. For 1992 and 1993, Fig. 8 gives average unemployment spells for those leaving unemployment to jobs. While the spell distributions have shifted over the two years, as would be expected, it is notable that between $60-80 \%$ of those leaving registered unemployment left within four months. In short, for those transiting through unemployment to jobs, the average unemployment spell was short; over a third of job finds were achieved in under a month in 1992 and roughly a fifth in 1993.

Nevertheless, we can observe a decline in the aggregate outflow rate, as also the outflows to jobs rate, in 1994. This change can be explained in terms of labor supply decisions as also by changes to job creation on the part of firms. Given the contractionary macroeconomic stance of government in the last half of 1993, it seems likely that aggregate demand effects have dominated 
leading to a decline in vacancies and in flows out of unemployment. As benefits levels have remained very low -- reaching on average no more than 15 percent of the mean wage in 1993 -declining search intensity seems an implausible explanatory factor.

While the employment decisions of firms is outside of the scope of this paper, the flows out of unemployment to jobs hints at one of the particular features of the Russian transition; the persistence in hiring. In any quarter of 1992 and 1993 roughly $5 \%$ of the labor force made a job transition. Obviously, a good part of these transitions took the form of job to job transitions. But the important result is that unlike in Eastern Europe where unemployment turnover is very small relative to measured flows of workers and jobs, in Russia unemployment - at least as yet -cannot be characterized as a stagnant pool ${ }^{7}$. And it is clear that most of the change in registered unemployed can be explained by changes to flows in rather than out of unemployment. This is not surprising if we think of transition as a major shock to demand that cannot be accomodated by natural wastage and small adjustments. Rather the enduring question concerns the reasons for why the inflow rate has remained relatively low, given the size of those adverse shocks.

\section{Distribution of Registered Unemployed by Duration , 1992-94}

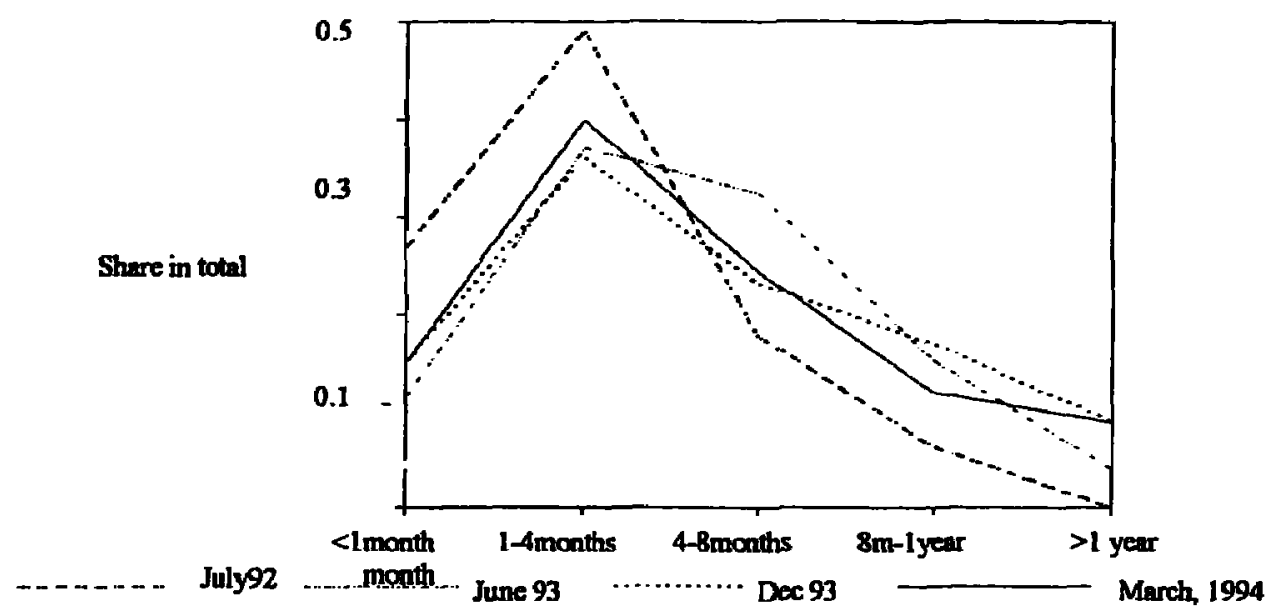

\section{Figure 9}

One implication of the above is that average duration of unemployment remains quite low and the persistence that now characterizes Eastern Eurcpe and many OECD countries has yet to emerge. Part of this, of course, arises through expiration of benefits and the shift to nonparticipation. Fig. 9 is revealing with respect to the distribution of registered unemployed by

\footnotetext{
${ }^{7}$ For Eastern Europe, see Boeri (1994).
} 
duration for four observations between July 1992 and March 1994. Roughly half the registered unemployed were experiencing a current spell of under four months at any of these points in time. Long term unemployed (those in a current spell exceeding one year) at the last time observation were under $10 \%$ of the total stock. The overall picture is thus of relatively small flows to unemployment, alongside large job-to-job flows, with high outflow rates and low unemployment durations. But the picture is regionally diverse, as we show in Section 3 below.

\subsection{Size and characteristics of the unemployed: survey evidence}

We have seen from the discussion above that Russian unemployment appears to have fallen in a surprisingly stable band of between $5 / 6$ percent since 1992 . Registered unemployment has climbed more sharply. But given imprecision in measurement, we choose to complement this data with information from a nationwide and representative sample survey of nearly three thousand individuals administered in May 1994. This section is based on the responses of 316 individuals who reported being either without work or were currently in either a spell of shorttime work or involuntary leave; the latter brackets an attempt to get some idea of the size and consequences of hours adjustment by firms.

\subsection{Magnitudes}

The distinction over those without work and those with some residual attachment to the firm is potentially important, particularly if we think of hours adjustment as a possible measure of any employment overhang. The raw information on the distribution over these three basic categories indicates that 7.8 percent were unemployed, 5.5 percent were on short time work and a further 3.1 percent were on involuntary leave. Table provides some idea of the size of the hours adjustment implied by either involuntary leave or short time status. Clearly, those on involuntary leave have generally been subject to far larger hours contraction, even if the motivation for picking for that hours adjustment, as well as the duration, is common across both categories. In short, it appears that in March 1994 nearly 16.5 percent of the labor force was either without work or else subject to some measure of hours adjustment. As we shall see, taking these numbers at face value is misleading and significantly overestimates the scale of labor underutilization. 
Table 3: Short Time and Involuntary Leave: Adjusted Hours, Spells and Reasong

$\begin{array}{cccc} & \text { Short time } & \text { Involuntary leave } \\ \text { Mean hours worked } & 25.3 & 9.1 \\ \text { Distribution of spells: }<6 \text { months } & 38 \% & 37 \% \\ & 6-12 & 22 & 20 \\ & 12-24 & 6 & 3 \\ & >24 \text { months } & 1 & 0 \\ \text { Reasons: Lack of demand } & 42 & 40 \\ \text { Firm arrears } & 27 & 17 \\ \text { Inputs shortages } & 24 & 30 \\ \text { Plant overhaul } & 4 & 3 \\ \text { Labor disputes } & 1 & 0 \\ \text { Other } & 2 & 8\end{array}$

Table is an attempt to provide in summary form some of the characteristics that make the first inspection somewhat misleading. A number of features are important. In the first place, roughly 6 percent of the sub-sample were effectively non-participants and conducted no job search (Category 2). A sub-sample of those on involuntary leave appear to have been acting as temporary lay-offs in the expectation of restarting work with their current employer (Category 3). And it interesting to observe that nearly half of those waiting were in full time work by the following month (April 1994). More significantly, most who were on an involuntary leave spell had found aiternative employment, generally of a secondary or informal nature. What is meant by secondary work? In half the cases of reported secondary work, this involved self-employment, almost exclusively in trade and services. The other significant source of such work was in private firms ${ }^{8}$. Those on involuntary leave and severely reduced working hours can be split into two groups. The first (Category 4) includes workers with less than 20 hours per week in primary employment. The second group comprising roughly two thirds of those on short time (Category

\footnotetext{
${ }^{8}$ However, part of this secondary work is probably parasitic on or related to primary state employment. Survey results for mid-1993 had nearly $\mathbf{4 0}$ percent of secondary work respondents doing this work 'after-hours'; a feature also found in De Melo and Ofer (1993).
} 
5) includes workers with less hours adjustment; the mean was 30 hours per week in primary employment. These workers had little secondary activity, in part because the mean contraction in hours was no more than 25 percent. The final group (Category 6) mainly incorporates workers without primary employment but with very significant secondary or informal work. Their mean income was notably higher than for the other categories.

Table 4: Characteristics of unemployed and marginally employed, March 1994

in \% to Total Sample

*w/o primary job

*in involuntary leaves

*on reduced work week

Registered at FES

Spell > I year

Receiving benefits

Exit rate to full time

job in April, 1994

Mean income per

family member, rubles

Females

Mean age (years)

Primary education

Higer education

Never worked full time

Living in rural areas

\begin{tabular}{|c|c|c|c|c|}
\hline Category 1 & Category 2 & Category 3 & Category 4 & Category 5 \\
\hline $3.5 \%$ & $0.6 \%$ & $0.6 \%$ & $1.4 \%$ & 2.9 \\
\hline $90.4 \%$ & $100.0 \%$ & $0.0 \%$ & $0.0 \%$ & 0.0 \\
\hline $7.7 \%$ & $0.0 \%$ & $100.0 \%$ & $33.3 \%$ & 13.8 \\
\hline $1.9 \%$ & $0.0 \%$ & $0.0 \%$ & $66.7 \%$ & 86.2 \\
\hline $50.0 \%$ & $0.0 \%$ & $0.0 \%$ & $4.8 \%$ & 6.9 \\
\hline $17.3 \%$ & $42.1 \%$ & $0.0 \%$ & $9.5 \%$ & 4.6 \\
\hline $28.8 \%$ & $5.3 \%$ & $0.0 \%$ & $0.0 \%$ & 0.0 \\
\hline $3.8 \%$ & $0.0 \%$ & $47.1 \%$ & $21.4 \%$ & 32.2 \\
\hline 58.840 & 68.111 & 41.333 & 62.128 & 83.00 \\
\hline $58.7 \%$ & $68.4 \%$ & $70.6 \%$ & $54.8 \%$ & 60.9 \\
\hline 34 & 33 & 41 & 41 & 4 \\
\hline $21.2 \%$ & $31.6 \%$ & $11.8 \%$ & $21.4 \%$ & 9.2 \\
\hline $13.5 \%$ & $5.3 \%$ & $5.9 \%$ & $7.1 \%$ & 27.6 \\
\hline $12.5 \%$ & $15.8 \%$ & $0.0 \%$ & $7.1 \%$ & 2.3 \\
\hline $26.0 \%$ & $47.4 \%$ & $17.6 \%$ & $4.8 \%$ & 16.1 \\
\hline
\end{tabular}

Category 1 = True unemployed

Category $2=$ Non-participants

Category $3=W$ aiting for re-employment

Category 4 = Employed part-time

Category 5 = Reduced work time, but near full time

Category 6 = Secondary employment

Source: World Bank/VCIOM survey, April, 1994 
In short, the share of the labor force that can be measured as unemployed in an ILO/OECD sense does not exceed 5.4 percent ${ }^{9}$. A further 4 percent were on involuntary leave or were experiencing severe working hours reduction with little or no immediate and alternative employment options. How notional was their attachment to the original firm appears to differ. But the majority of those on involuntary leave were clearly experiencing a temporary spell. Further, an additional 7 percent of short-timers were actually near to full time work in their primary - state -- employment or else were working full time in the informal sector. This suggests that taking involuntary leave and short time along a continuum, the choice of the former correlated with the size of shock experienced by firms. But -- importantly -- nearly a third of those working to a significant degree in the informal sector were registered as unemployed and just under a quarter were receiving benefits ${ }^{10}$.

Our survey results for aggregate unemployment thus suggest that even by the end of the first quarter of 1994 those strictly unemployed were just over 3 percentage points higher than registered unemployed. One percent of the labor force in our reference period had passed to nonparticipation and the likely immediate 'employment overhang' -- concentrated in Categories 3 and 4 -- amounted to no more than 2 percent of the labor force.

\subsection{Who and where are the unemployed?}

Focusing on our measure of the 'true unemployed' (Category 1), we now turn to some simple attributes. Given data limitations, at this stage we can only explore characteristics within our universe of unemployed and hours-adjusted workers. In other words, the reported results are conditional on being in this sample and hence are clearly biased ${ }^{\text {"1 }}$. We estimate some simple probit equations relating current status to a set of variables summarizing individual-specific information and including age, gender, educational level and location. Table 5 gives the main results. The story is that the probability of being 'truly' unemployed is positively associated with the education level and with certain types of workers, mainly clerical staff. Being laid-off is a

\footnotetext{
${ }^{9}$ VCIOM estimates for June 1993 are 6.2 percent against 6.7 percent in April 1994. They are higher than those we give as they consider the unemployed to be those without primary work and not working at home. But assuming the same distribution, one conclusion is that there is little trend.

${ }^{10}$ Hardly surprising, of course, considering the level of benefits and the monitoring abilities of the Employment Service.

"We will shortly be able to get a fuller picture with information for the full sample of 2935 individuals.
} 
good predictor of unemployed status but the size of the coefficient and its significance is little different from that for quits, possibly suggesting that the latter category may camouflage an involuntary component. There also appears to be a link from location to unemployment; those in medium sized towns and in oblast centers appear to have a slightly high risk of being unemployed.

Table 5: Probit estimations

\begin{tabular}{|c|c|c|c|c|}
\hline \multicolumn{3}{|c|}{ Dependent Variable: Category 1 status } & \multicolumn{2}{|c|}{ Category 6 status } \\
\hline Variable & Coefficient & T stat & Coefficient & T stat \\
\hline Age & -0.023 & -2.833 & -0.623 & -1.199 \\
\hline Higher & 1.198 & 1.566 & 0.559 & 2.069 \\
\hline Firm liquidated & 1.233 & 2.564 & 0.196 & 0.354 \\
\hline Mass lay-off & 1.645 & 7.308 & 0.501 & 1.986 \\
\hline Quit & 1.56 & 5.552 & 0.685 & 2.436 \\
\hline Professional/ITR & -0.289 & -1.154 & -0.054 & -0.197 \\
\hline Clerical & 0.433 & 1.649 & -1.039 & -2.118 \\
\hline Female & -0.208 & -1.155 & -0.315 & -1.578 \\
\hline Family Size & -0.048 & -0.723 & 0.101 & 1.87 \\
\hline Large City & 0.412 & 0.897 & 0.371 & 0.857 \\
\hline Medium & 0.548 & 1.643 & -0.349 & -1.003 \\
\hline Oblast center & 0.340 & 1.047 & -0.142 & -0.437 \\
\hline Rural & 0.417 & 1.221 & -0.060 & -0.171 \\
\hline Constant & -0.245 & -0.510 & -0.623 & -1.199 \\
\hline
\end{tabular}

The results of a similar exercise for our Category 6 -- those with significant secondary or informal work -- suggest that education level is positively associated with this status and with location; residence in cities may be important. The signs on the variables summarizing the transition to this status are similarly signed with comparable magnitudes as for the "true unemployed'. The negative terms on both the age and gender terms points to the dominance of youinger males in this category.

As regards sectors of original attachment, over two thirds originated in state firms, broadly defined with a further 6 percent originating with privatized entities and 7 percent from private firms. Sectors of origin correspond quite neatly to the national distribution and the employment distribution for the entire sample, with over 40 percent originating in industrial firms.

Finally, we are able to get some idea of the spatial distribution of the unemployed. This suggests that the share of the unemployed in large cities and their environs, as also in medium 
sized towns, is significantly lower than in the sample population as a whole. Second, like in Eastern Europe unemployment appears to have a rural bias and longer term unemployed seems to be disproportionately distributed in rural areas. And unemployment in the oblast centers was reported at least 5 percent higher than for the sample mean.

\subsection{Determinants of registration}

We have found that just over a quarter of the total sample of 316 individuals had registered as unemployed. Half of the 'true unemployed' had registered and they comprised over 60 percent of total registrees. Interestingly, 18 percent of the registered were people with significant informal or secondary work and they further accounted for 26 percent of all benefits recipients. In other words, registration does appear systematically to exclude people with some form of primary employment.

But to explore the relationship for those without primary or formal employment between registration and receipt of benefits in more detail we ran two probit equations relating those states to various indicators. Table 6 presents the results.

Table 6: Determinants of Registration and Receipt of Benefits; probit estimations

Dependent Variable: Registrations ( $\mathrm{n}=66$ )

Constant

Unemployed with spell $<6$ months

Unemployed with spell 6-12 months

Lost job through firm liquidation

Laid off in mass lay-off

Never worked full time

Dependent variable: Receipt of Benefits ( $n=55$ )

Constant

Without primary job

With secondary job

Lost job through firm liquidation

Laid off in mass lay-off

Female

Number of family members

[* = significant at 5 percent level]
$-1.39 *$

0.51

$1.07^{*}$

$1.69 *$

$1.36^{*}$

1.50
$-1.66^{*}$

1.23*

$0.93^{*}$

$0.91^{*}$

1.08*

0.16

$-0.11$ 
Registrations are clearly positively associated with length of current unemployment spell and with the type of separation that induced the current unemployment spell. Workers subject to involuntary separations tend to register, as do new entrants. Receipt of benefits is evidently related to lack of primary employment and the involuntary nature of the separation but there is a positive and significant coefficient on the secondary employment term . By contrast, age, gender, professional status and location appear to play no significant role in governing the decision on registration or subsequent receipt of benefits.

\subsection{Transitions and search}

Focusing first on the 'true' unemployed, what routes were taken to this state? Nearly 45 percent were involuntarily separated, the bulk of which were through closures or mass layoffs. But -- not surprisingly, given the information presented in Section 1 -- as much as 35 percent had quit their previous employment. This feature is likely related to the relatively high turnover in unemployment that we have already indicated. And indeed 25 percent of this category expected on entering unemployment to find a job immediately or in a far smaller number of cases to be recalled by their former employer.

Mapping the respective transitions across jobs, unemployment and non-participation is at this stage only possible for a sample of 223 individuals across our six categories. The results are quite revealing and are summarized in Table 7. Rough hazard rates, classified in terms of the impulse to a transition (a quit, involuntary separation etc.), are calculated. Transitions to other jobs are however over-estimated as they refer to job offers and, at least for offers made through Labor Offices we know that refusals are not uncommon ${ }^{12}$. Nevertheless, several points are worth emphasi ing. First, the hazard to jobs rate is quite high for all types of separations as for new entrants. Further, nearly 60 percent of those transitions to jobs were made to secondary or informal activity and the probability of either a quitter or a new entrant moving to an informal job was very significantly higher. In addition, 13 percent of the sample made a direct job-to-job transition. Second, near on 10 percent moved to non-participation, with this route significantly more likely when the separation decision was voluntary. This evidently picks up the flow of older workers and women to out of the labor force. Third, for over 30 percent of those making a

\footnotetext{
${ }^{12}$ For mid-1993 a VCIOM survey of 1016 registered, urban unemployed indicated that for those receiving job offers roughly 50 percent made one or more refusal.
} 
transition, unemployment was the destination, with clearly higher probabilities attached to workers separated by mass lay-off or firm liquidation's and new entrants.

Table 7: Factors inducing a job transition and probable new status of those leaving a job

\begin{tabular}{|c|c|c|c|c|}
\hline $\begin{array}{l}\text { Transition } \\
\text { Route }\end{array}$ & Share & $\begin{array}{l}\text { Non-Partic- } \\
\text { ation }\end{array}$ & $\begin{array}{l}\text { Primary } \\
\text { Work }\end{array}$ & $\begin{array}{l}\text { Secondary } \\
\text { Work }\end{array}$ \\
\hline
\end{tabular}

Liquidation/ .33

.10

.25

.15

.50

Laid-off

Other Invol- . .11

.11

.63

.37

.40

Separations

Quits $\quad .24$

.25

.20

.20

.35

New Entrants.16

.10

.27

.73

.52

Job-to-job $\quad .16$

.86

.14

\section{Source: World Bank/VCIOM survey}

While it appears that registration rates were reasonably high, job search was predominantly done through friends and relatives. This was a common pattern across all those who registered. It is clear that responses to posted vacancies and visits to firms were also important, but it is revealing that nearly 20 percent of the registered attached little or no probability to finding a job through the Employment Office. The institutional matching of workers to jobs appears not to be that powerful. And the general impression is of information and other inefficiencies in matching that translate into longer search times and a reasonably high level of job rejections for offers generated through Employment Offices.

The spatial scope of job search is obviously important. Due to institutional (e.g. propiska) and other rules mobility across regions remained very limited. The survey suggests that this is a clear stylization we can accept. Almost two thirds of the sample (Categories 1-6) when asked what preconditions existed for moving to work in another region replied that under no circumstances would they be induced to move. Higher wages or employer provided housing or employer-borne reallocation costs were cited by only 25 percent of respondents as being meaningful preconditions. For the 'true unemployed' the distribution of responses was very similar. A probit estimation relating the refusal to move to a set of individual or household 
attributes indicated that older individuals, inhabitants of cities and those with higher skills have a clear low propensity to accept mobility. The inverse appears to hold for rural and medium sized town residents but few of the coefficients are significant. The implications of such apparent labor immobility for relative regional unemployment is explored in more detail in Section 3 below.

\subsection{Durations}

For the 'true unemployed' the exit rate to full time employment in March was 4 percent and hence quite close to the 5 percent exit rate for all registered unemployed reported by the Federal Employment Service. This exit probability is quite low and would imply an expected completed duration in excess of two years in steady state. Yet looking at the distribution of current unemployment spells we find that the average spell was no longer than six months, with over three quarters of the true unemployed currently in an unemployment spell of under one year, with the majority under six months (Table 8). The evident impression is that long run unemployment has yet to emerge.

Table 8: Unemployment spell for 'true unemployed' (Category 1)

\begin{tabular}{|cc} 
Average spell: & 6 months \\
Including new entrants (n=104) & \\
$<6$ months & $42.3 \%$ \\
$6-12$ months & 34.6 \\
$12-24$ months & 10.6 \\
$>24$ months & 6.7 \\
No response & 5.7 \\
New entrants (n=13) & \\
$<6$ months & $69.2 \%$ \\
6-12 months & 30.8 \\
Excluding new entrants (n=91) & \\
$<6$ months & $69.2 \%$ \\
6-12 months & 35.1 \\
$12-24$ months & 12.0 \\
No response & 6.8
\end{tabular}

Source: World Bank/VCIOM survey, April 1994 


\subsection{Income}

We are constrained in the analysis by having only one income measure; average income per household for March 1994. However, the variation in family size is small across all categories. This suggests that family size differences are unlikely to be a major explanatory factor behind variation in average income. Second, while there is clear and large dispersion in income within categories, the variation is mean income across categories is less than we might have expected, considering regional and other particularities.

\section{Distribution of Income, April 1994}

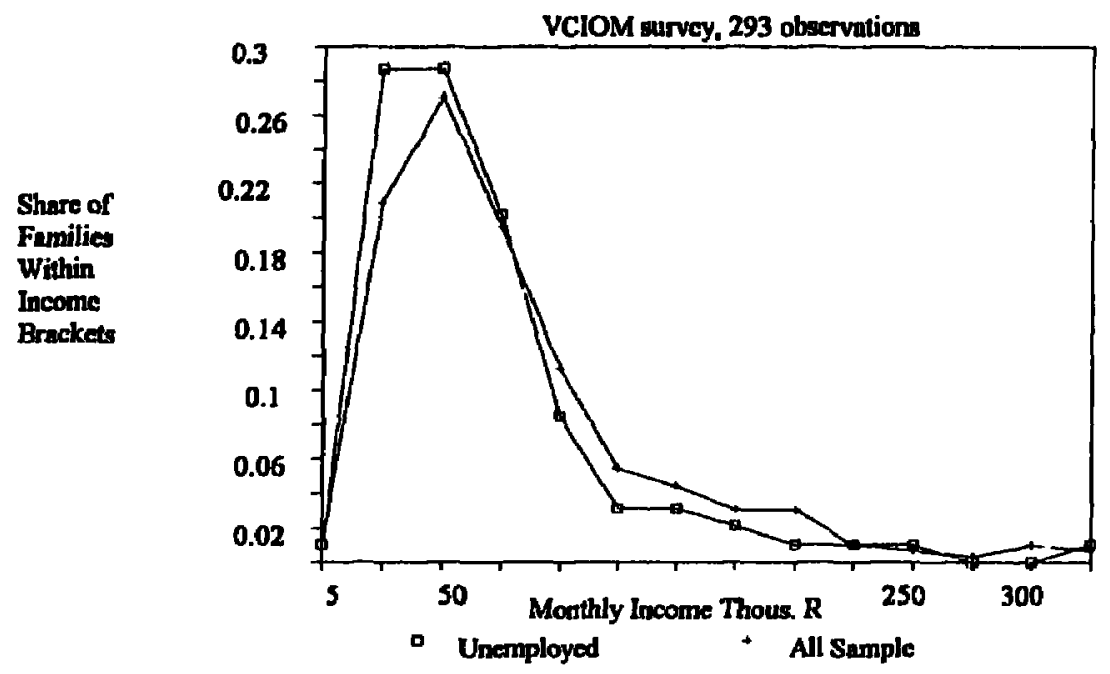

\section{Figure 10}

Fig. 10 provides the distribution of monthly income separating out the unemployed from the other categories in our sample. The distributions are fairly similar, though the unemployed have an obviously higher share of families at toward the tail of the distribution. Average income for 'true unemployed' households was around 85 percent of the mean for the fuller sample (Categories 1-6) and just under 75 percent for the total sample ${ }^{13}$. Clearly, those without work or partially employed do have low relative reported incomes as indicated by the true unemployed with a mean income under 60 percent of the national mean as well as those on voluntary leave without secondary work (Category 3). Yet it is worth stressing that workers with substantial

\footnotetext{
${ }^{13}$ The mean per caput income for the total sample (viz.; 2935 individuals) was 79,945 rubles. This is very significantly below the number - 125,000 Rubles - given by Roskomstat for March 1994. The first is more likely to be a proper measure as the latter include notional tax rebates and wage arrears in their estimates of current income.
} 
secondary work and those on limited short time report average incomes in excess of the larger sample mean. Taking the ratio of the income of the unemployed to the range over Categories 5 and 6 as parodying the relationship between the reservation wage and its mark-up, the picture is of a 40 percent gap. This appears to be true both with respect to income derived primarily from state sector work as from largely self-employment or private sector work.

We experimented with a standard logarithmic incomes function where the vector of independent variables includes those indicating different levels of education and skill, current or former attachment and other characteristics ${ }^{14}$. The estimation indicates reasonably conventional returns to education and skills. Average income is significantly and negatively associated with current or prior attachment to state firms, including industrial firms, as well as a rural location. Income is quite clearly negatively associated with being unemployed - as measured by our Category 1. By contrast, there is an unambiguously positive association with secondary work .

\section{Regional Dimensions}

\subsection{Framework}

Figures 11 and 12 highlight the emerging differences in regional unemployment rates, as measured by registrations and by an adjusted measure where involuntary leaves are included. Both measures are biased; the first downwards; the latter upwards. Even so, they show quite strikingly how large has been the range of departure from neas-full employment. Taking registrations data first, by early 1994 we find a range of 0.5 - 8 percent across regions; for the adjusted measure the range extends from $2-28$ percent. Where we can correct the involuntary leave component by an average spell per region per quarter, the range shifts to $1-11$ percent. So whatever measure we use, several common features stand out. Relating unemployment over these two measures in mid-1992 to the levels in early 1994 we find very significant and across the board increases across oblasts. The dispersion in unemployment rates across regions is clearly increased once we inclucie involuntary leave. At mid-1992 the coefficient of variation in the unemployment rate was 0.4 , by 1994 it had shifted to 0.7 .

\footnotetext{
${ }^{14}$ Obvioushy this is not that informative, as the data relate only to individuals in the sample of 316 unemployed or under-employed workers. The main finding for this sample is that income is negatively associated with being 'truly unemployed'. Results available on request from the authors.
} 


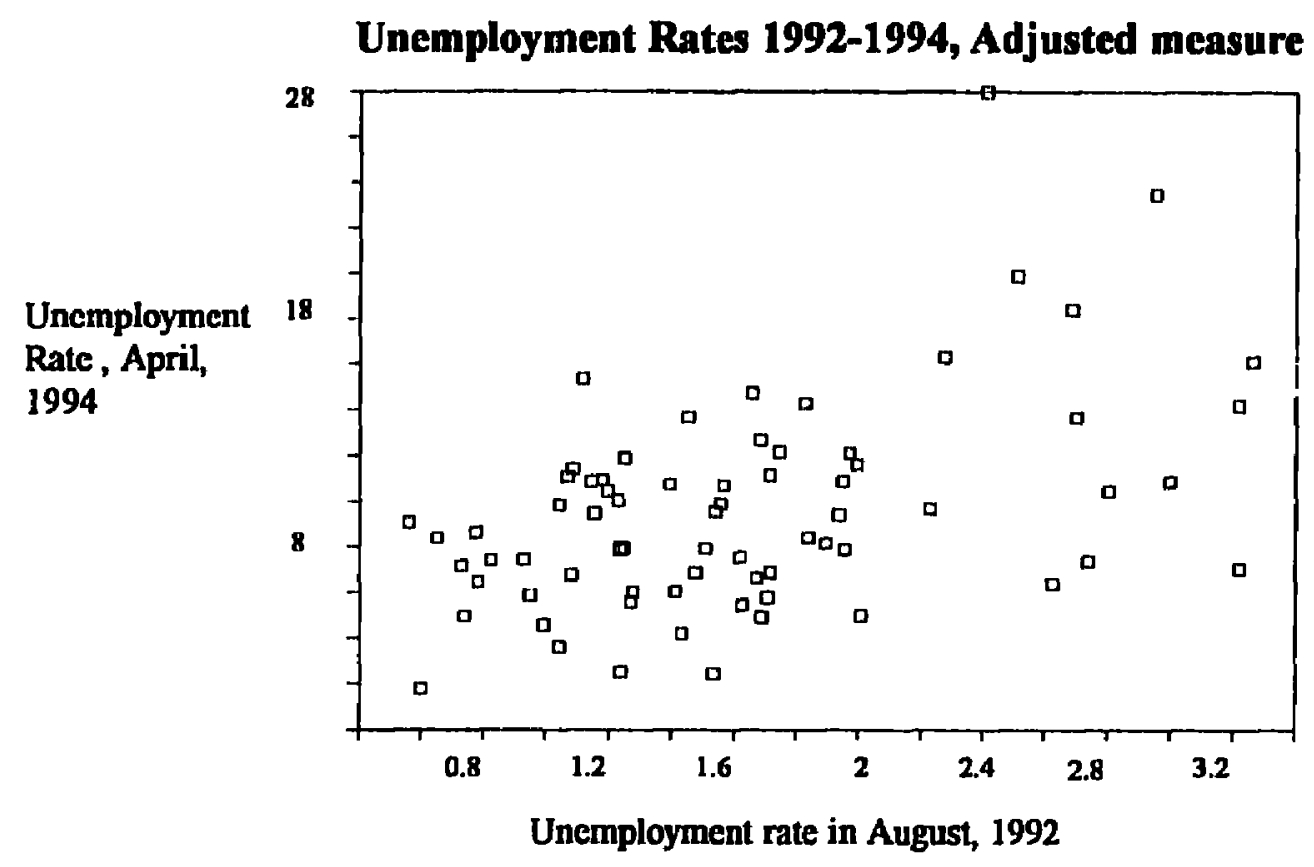

Figure 11

Unemployment Rates 1992-1994, Registration Data

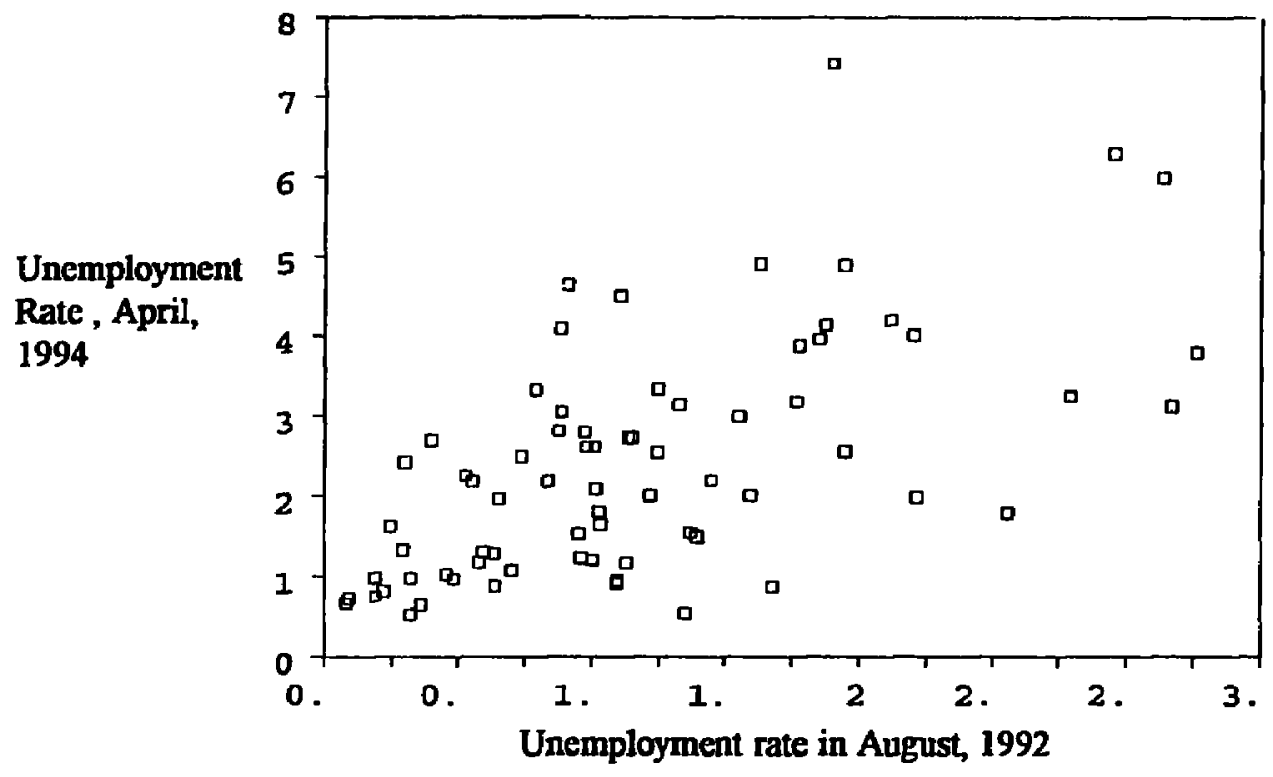

Figure 12

This dispersion in regional unemployment rates is hardly surprising, after all different regions have received different magnitudes of shocks. What is more interesting - and obviously more difficult -- is to understand how divergent regional unemployment will remain and for how 
long. Certainly, we can see few reasons for convergence in the forseable future. Absence of the earlier equalization mechanisms -- particularly of a fiscal nature -- would accentuate divergence as would the absence of labor mobility. We have seen from the survey results that the unemployed, for example, are extremely reluctant to move in line with wage or other advantage. And this is doubtless consolidated by institutional and other restraints on inter-oblast mobility of labor.

Regions produce different mixes of goods and hence experience potentially quite different shocks to labor demand. Shocks to a region's labor demand ought to lead to changes in relative wages and employment; assuming that they face a broadly similar macroeconomic environment. In practice, in Russia regional administrations appear to exercise large discretion, extending to price controls as well as wage and employment decisions. For instance, they may choose to slow the rate of employment decrease through hours adjustment rather than picking separations as the response to an adverse labor demand shock. These components may lead us to think that in the short run at least shocks will generate different responses. But a key feature that differentiates Russia, say, from North America is the far lower degree of factor mobility. In particular, little or no movement of workers across regions can be expected in response to a shock. Empirical work on the US, for example, indicates that while shocks to relative region employment tend mostly to be permanent, this is not the case for relative unemployment. The latter is untrended with little persistence. Blanchard and Katz (1994) explain this largely as a function of worker mobility. Adverse labor demand shocks impel workers to move with the result that while employment may not increase, unemployment will fall as workers migrate. A further finding is that relative nominal wages have not declined sufficiently to prevent increases in unemployment and there has been quite strong convergence over time in relative wages.

These findings from a context of high factor mobility are suggestive once we start thinking about Russia. In the first place, once the system is constrained in terms of factor mobility we might expect adverse labor demand shocks to regions to lead to differences in employment and unemployment changes which would be quite large and persistent. We could, for example, imagine that an inability of workers to move, coupled to relative wage rigidities arising from the institutional setting and associated to the one country setting, would result in relative unemployment being strongly trended and persistent. 
Further, while workers cannot in general move, this constraint may be less binding for firms who can pick regions. Below, we make the probably optimistic assumption that capital is mobile in Russia. This implies that while relative regional wages will be unaffected by labor movements, decisions on job creation could be affected by relative regional wages. The sensitivity of relative nominal wages to region conditions is obviously critical. The greater the degree to which region wage setting is dissociated from region activity levels, as through a national wage rule, the weaker the likely play-back from relative region wages to job creation. We provide a more formal presentation in the model written in Appendix 1. While it is clear that at this stage we have limited options for directly confronting regional data in a manner consistent with our model, we can begin to look at the respective relative movements in wages, employment and unemployment. We turn first to wages.

\subsection{Wages and their relative paths}

We start with what we know about the wage path at an aggregate level. Fig. 13 demonstrates that real consumption wages have hardly moved from the floor set after the January 1992 price shock $^{15}$.

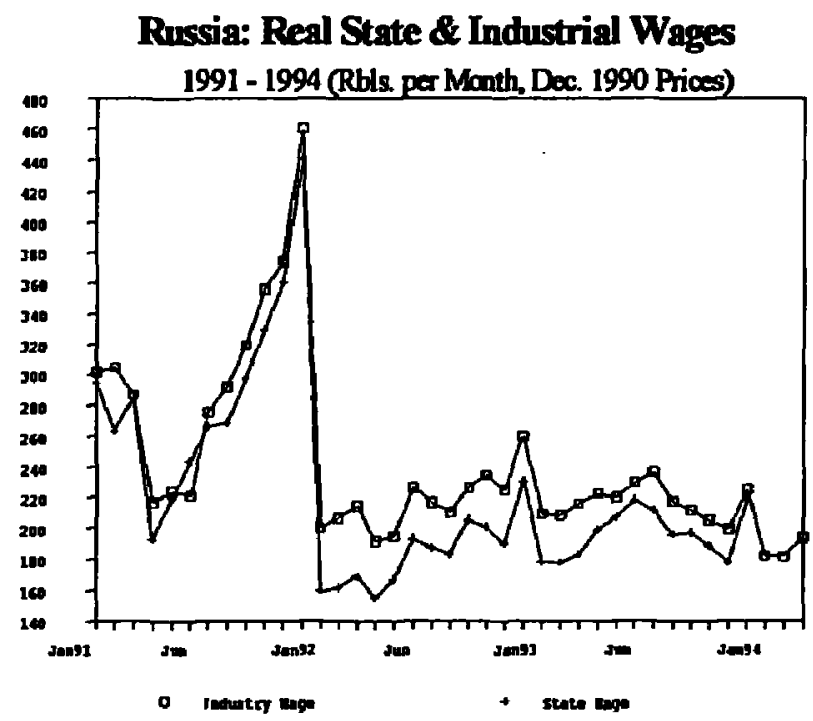

Figure 13

\footnotetext{
${ }^{15}$ This is not true for dollar wages which expanded by over ten times between January 1992 and early 1994, largely through the real ruble appreciation that occurred in 1993.
} 
This restraint cannot be mecahnically linked to the presence of a binding wage norm or system of constraints. As Fig 14 shows, the aggregate wage bill consistently exceeded the wage norm and by large cumulative magnitudes. Further, the absence of a punitive marginal tax rate on above-norm wage payments diluted the regulatory effect of the norm. However, the wage norm and the structure of regional relativities does inhibit the degree to which wages can be set at a regional level.

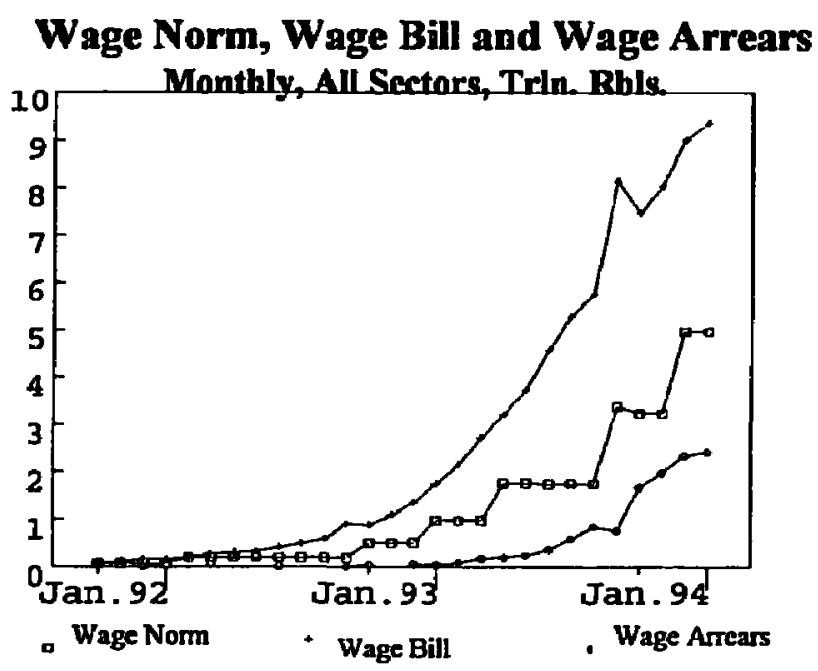

Figure 14

The apparent wage moderation that we observe in the aggregate is if anything magnified by the presence of wage arrears. Though these have been far from large through most of the recent period -amounting to under 10 percent of the aggregate wage bill and reasonably concentrated, and they have become far more significant in 1994. The obvious implication is that actual as against notional wages have commonly been smaller given the inflation tax on arrears. So, using aggregate information the clear impression is that wages have remained at low levels with little drift in the changes. A crude indexation to prices appears to hold until early 1994, at which point there is a downward shift.

The obvious question that we need now ask, in the light of the set-up above, is what has been the response at lower levels of aggregation and what does this tell us about the relative response of regions to relative shocks, assuming that a fall in the relative value of labor's product could be expected to reduce labor demand? The depth of this contraction will in part depend on whether or not wages can fully absorb the shock. A large relative shock should be associated with a comparable relative wage adjustment. And because benefits' levels have been very low - below subsistence levels - they have placed no significant floor on the potential adjustment. 


\section{Regional Wage: Initial Differences and Changes between 1st QQ of 1992/4}

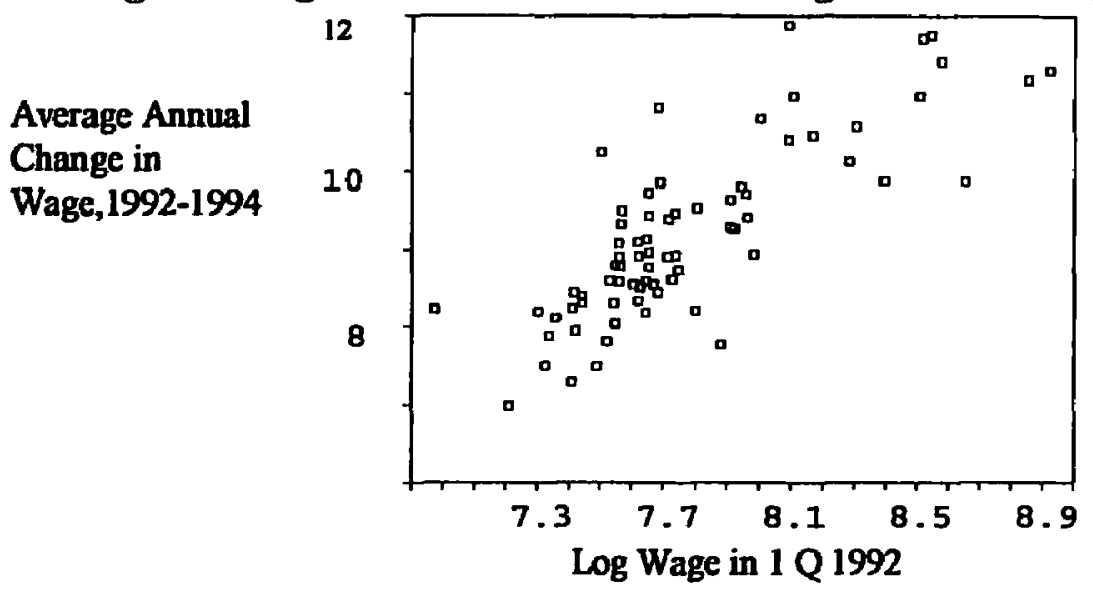

Figure 15

An obvious starting point is to examine the path of relative wages, employment and unemployment given the initial conditions. Fig. 15 does precisely that by relating the annual average change in nominal wages to the log wage in 1992.q1. The clear upward sloping line that could be fitted to this picture suggests strongly that wage changes have tended to act on and possibly amplify the initial structure of relativities. The same exercise is hard to repeat for region employment, partly because a comparable data series is not available save for 1993.q1 - 1994.q1. Fig. 16 attempts a similar exercise to that for wages. While again the fitted line would slope upwards, the amplification of the initial conditions is less and changes, given the reference, are more convergent. In addition, inspection of within period changes indicates that changes in relative employment within and across the sample period terd to be consistent. Finally, referring back to Figs. 11 - 12 we can see that relative region unemployment rates cannot be simply explained as an amplification of the earlier structure of relative rates, taken at August 1992. Both for adjusted and registered unemployment measures, we would be able to fit an upward sloping line, but, particularly with the first measure, we also find significant dispersion. 


\section{Unemployment and Employment Changes}

Unemployment change, 1994/92, rate

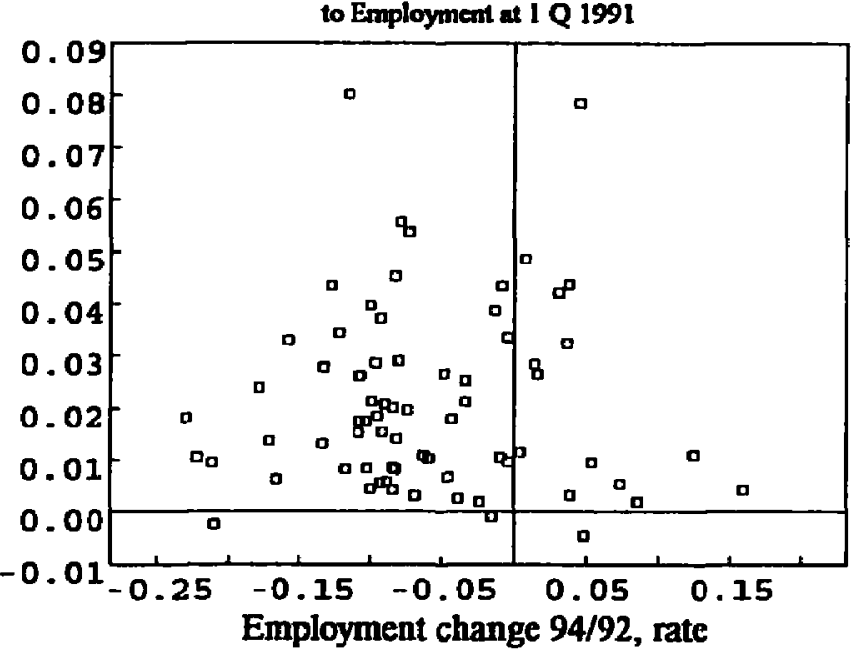

Figure 16

The above features beg the question of whether the changes in wages can be systematically related to changes in employment or ur.employment, using region observations. Clearly, in the presence of regionally differentiated shocks, we would expect not only different magnitudes of shock to employment but some clear play-back to wages. Given gaps in the employment series, henceforth we work with the unemployment numbers. As such we are assuming that relative region unemployment and wages are not simply expansions along the same distribution.

To sort these features out satisfactorily, we start with some simple scatters for the first quarter of each year from 1992 through 1994, relating changes in nominal wages to the adjusted unemployment measure, both variables being regional observations. The observations, including the data on which the regressions reported below were estimated, cover 72 out of the 79 oblasts in Russia. Figures 17-19 unambiguously charts the emergence of an apparently conventional link from region unemployment to region wages, so that by $1994 . q 1$ we observe a clear inverse association between the change in wages and unemployment. At the start of transition, we observe no evident relationship between a region's unemployment and changes to wages. Gradually, this changes and the sensitivity of region wages to region unemployment grows over time. 
Unemployment rates and Wage inflation, at 1 st quarter 1992

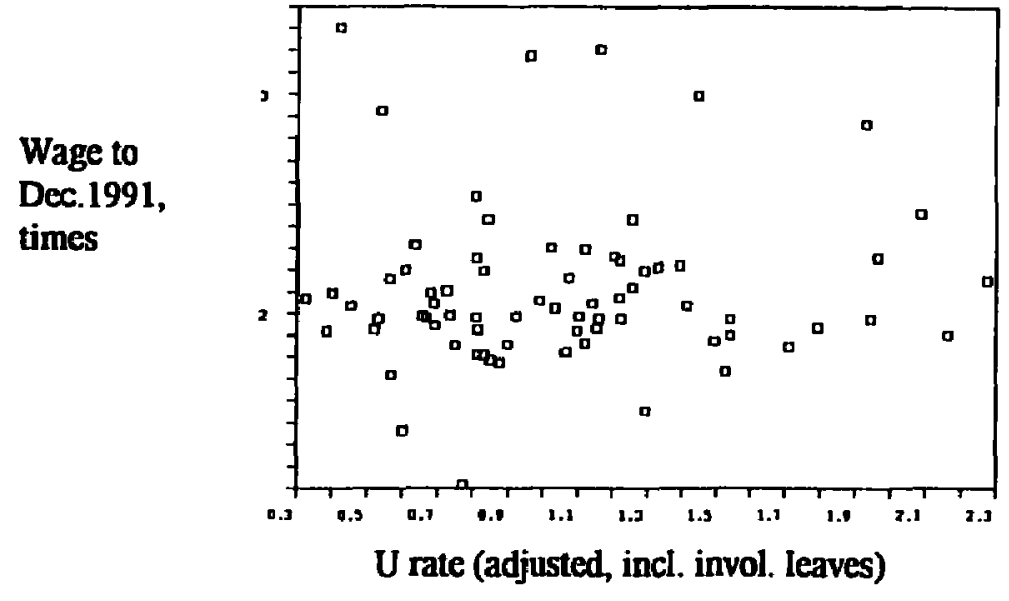

Unemployment rates and Wage inflation, 101993
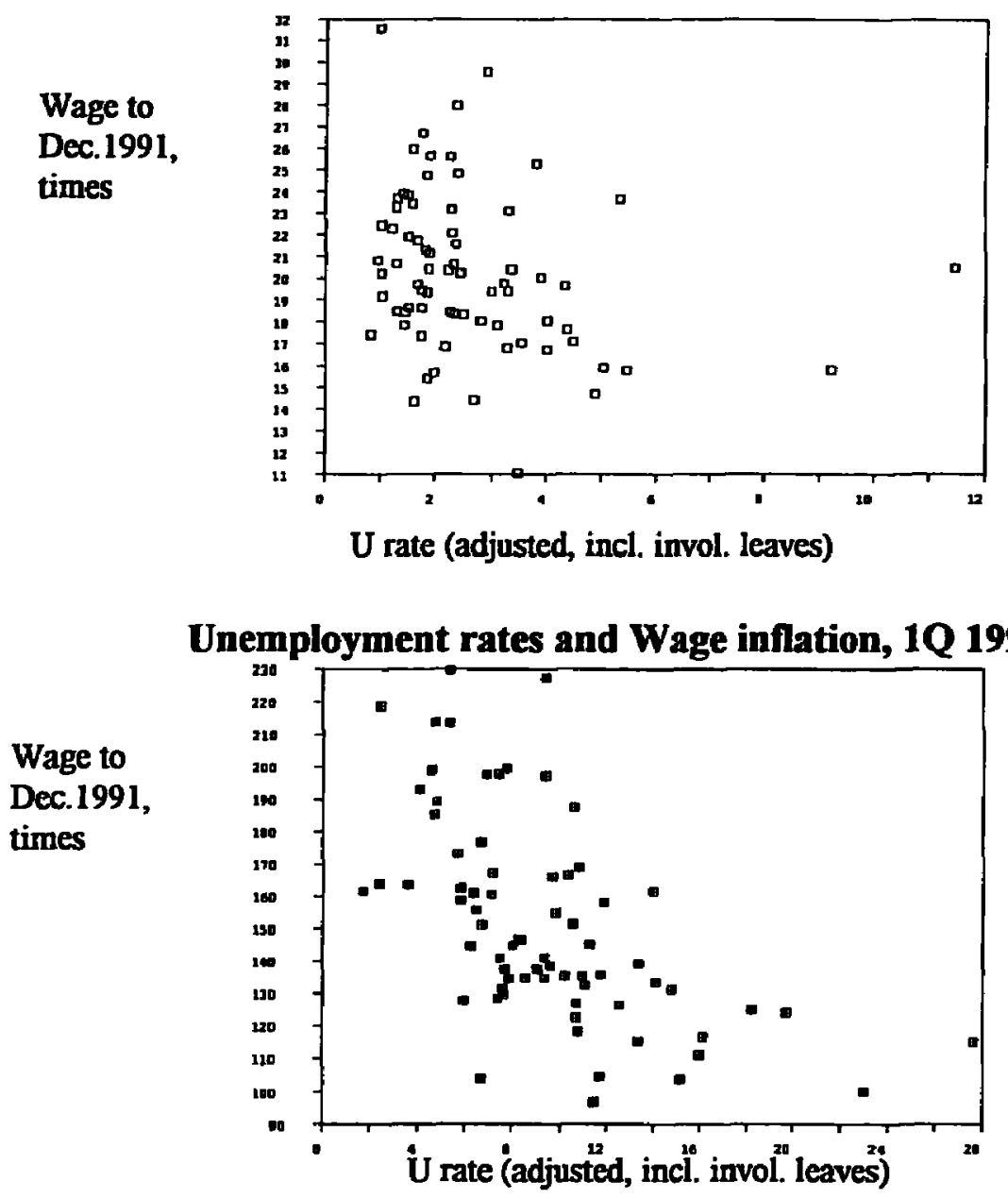

Figures 17-19 


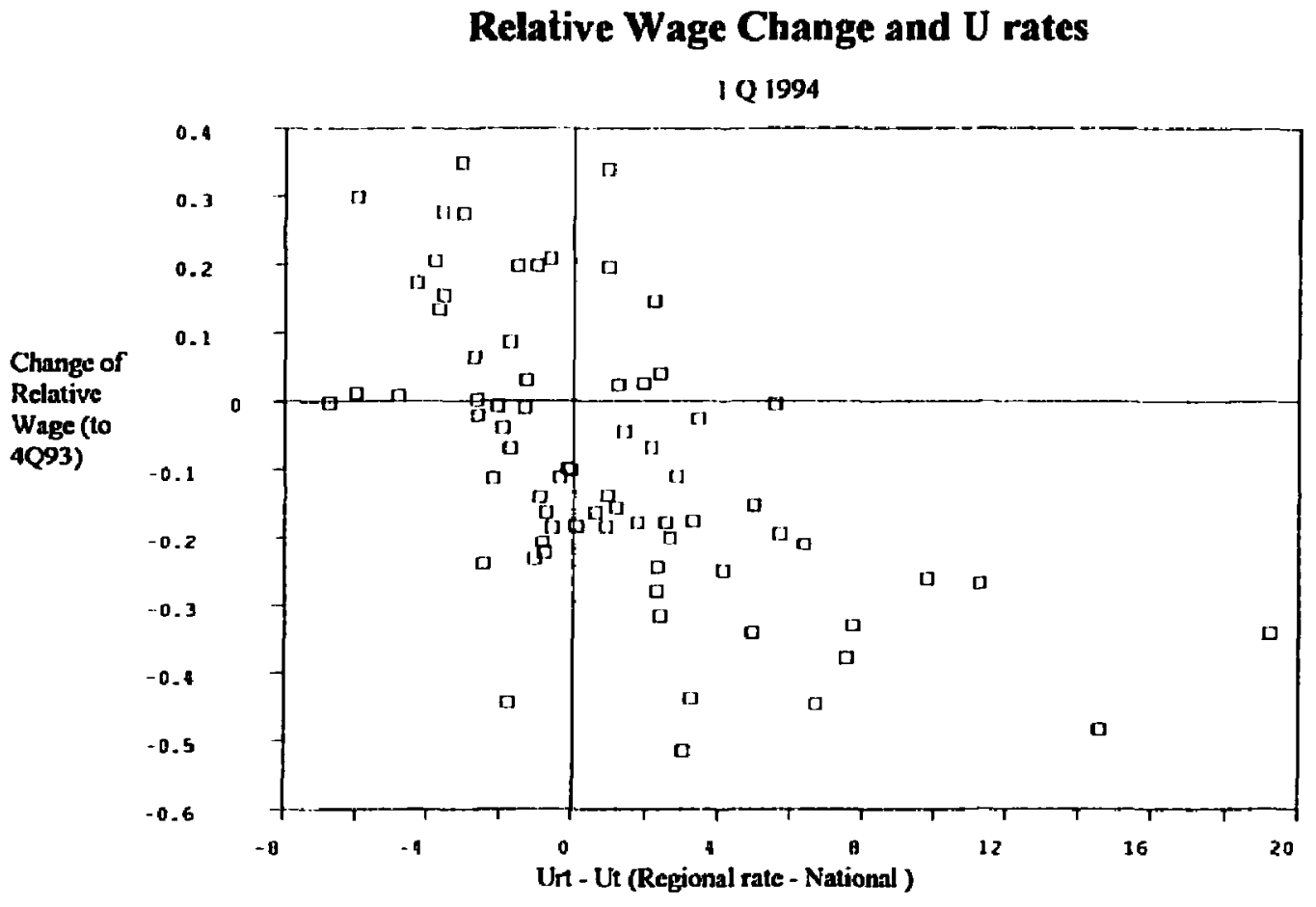

Figure 20

Further, Fig. 20 indicates for the same period that the change in a region's relative wage is inversely associated with a region's relative unemployment rate. In other words, regions with high relative unemployment rates in 1994.q1 experienced deterioration in their relative wages.

To explore the apparent emergence of this equilibrating mechanism, we set up a panel of monthly and quarterly observations allowing us to relate the change in region wages to region unemployment and current and lagged region consumer prices; a standard derivation of the Phillips curve ${ }^{16}$. The results were not particularly promising. While the coefficients were predictably signed and significant, both the quarterly and monthly estimations had low overall explanatory power. Further, the F statistic in the fixed effects estimate was very low, indicating too much variance within sample to warrant pooling. Indeed, inspection of individual region wage observations indicated very large variations across periods. This was true for both monthly and quarterly estimations. In addition, the likely sensitivity of the relationship to the time specification -- given the scatters presented above -points to use of cross sectional estimates. Accordingly, we re-estimate on two cross-sections, 1994.q1

${ }^{16}$ Of the form, $w_{r t}=\alpha_{1}-\alpha_{2} U_{n}+\alpha_{3} p_{n}+\alpha_{4}(1-\alpha) p_{n-1}$ 
over 1993.q1 and 1993.q1 over 1992.q1. The specification is in first differences and logs with the wage and price variables set up in index form and based to December 1991. Given the size of monthly inflation over this period, we suppress the use of a lagged price term. The results are listed in Table 10. The variables are predictably signed and significant at more than the 5 percent level, even if the size of the coefficients is quite small. However, the overall fit of the estimation improves over time.

Table 10: Wage equations: Cross-sections, 1994.1/1993.1 and 1993.1/1992.1

\begin{tabular}{|c|c|c|c|c|}
\hline DlnWage93 = & $\begin{array}{l}2.01 \mathrm{C}- \\
(19.23)\end{array}$ & $\begin{array}{l}0.01 \mathrm{U} 93 \\
(-1.78)\end{array}$ & + & $\begin{array}{l}\text { 0.14DlnRPI93 } \\
(2.81)\end{array}$ \\
\hline \multicolumn{5}{|c|}{$\mathrm{R}^{2}=0.14 ;$ s.e $=0.10 ;$ mean of dep variable $=2.26 ;$ Durbin Watson $=1.52 ; \mathrm{F}$ stat $=5.68$} \\
\hline DlnWage94 = & $\begin{array}{l}2.32 \mathrm{C}- \\
(11.82)\end{array}$ & $\begin{array}{l}0.02 \text { U94 } \\
(-4.45)\end{array}$ & + & $\begin{array}{l}\text { 0.29DlnRPI94 } \\
(3.11)\end{array}$ \\
\hline
\end{tabular}

At this stage, we can draw the conclusion that regional wage setting has begun to be more responsive to region unemployment. There is a clear inverse relationship between the unemployment level and changes to nominal wages, although the size of the price coefficient is rather low. Since transition began in Russia, changes to relative wages have very clearly dominated changes to relative unemployment or employment; reinforcing the general impression that wage flexibility in aggregate and across regions has been a powerful feature of the transition so far.

\subsection{Relative employment and mismatch}

The evolution of relative employment is less easy to deal with, largely because of data limitations. As a result, we have to limit ourselves to working with unemployment numbers, assuming that they can tell us pretty much the same (inverse) story. Here, our presumption is that changes to relative region employment will be potentially large and persistent.

That there is growing dispersion in both regional vacancy and unemployment rates is clear. Combined with what we know about labor mobility, we could reasonably expect to find rising mismatch in the labor market. Such mismatch could take several obvious forms; age, gender, skill and 
regional dimensions being those commonly explored. In our discussion, the regional mismatch is particularly interesting but it is also worth noting - though we are unable to go further with this at this stage - that the bulk of vacancies posted at Labor Offices have been for manual workers. At 1994.q1 these accounted for around 85 percent of total vacancies and the share has remained stable since the start of transition. Yet we also know that the bulk of involuntary separations have been concentrated on clerical and professional workers, a high proportion of whom have been women. This may suggest the presence of skill imbalances. In any event, it suggests that the matching of workers transiting in unemployment to jobs - a process we deal with below -- is likely concentrated on certain categories of workers.

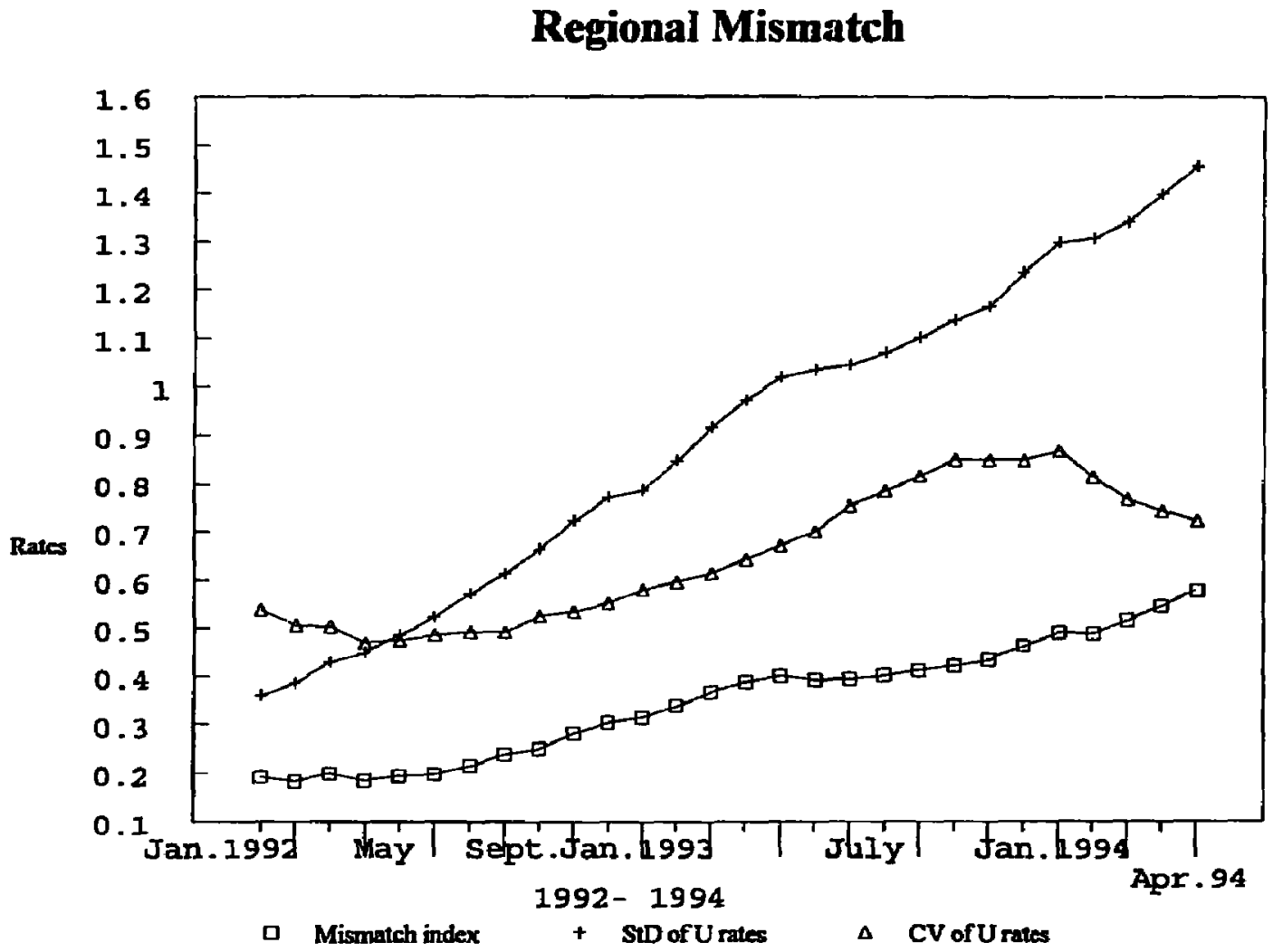

Figure 21

Turning to the regional dimension, lack of labor mobility could be expected to accentuate divergences in the distribution of unemployment and vacancies across regions. In Eastern Europe, the evidence suggests that regional mismatch between unemployment and vacancies has increased over time. Using regional data, we calculate a mismatch index that takes into account unemployment and 
vacancies ${ }^{17}$. The story is clear (Fig. 21). The index grows throughout the period rising from 0.2 to over 0.5 in 1994. Although cross-country comparisons are problematic, the measure points to quite high mismatch at an early stage in the transition. The same measure calculated for Poland in 1992, when regional dispersion in unemployment and vacancy rates was greater than in Russia through 1994, gave monthly mismatch in the region of 0.17 to $0.25^{18}$. And spatial mismatch would be one factor influencing the impact of vacancies on outflows to jobs from unemployment. We now explore in some more detail the way in which such outflows to jobs -- as the best proxy for hiring - responds to changes in the stock of unemployed and vacancies ${ }^{19}$.

\subsection{Efficiency in matching}

We have seen that, relative to Eastern Europe, flows out of unemploynent to jobs have been large. Our survey results pick out the importance of informal sector jobs and self-employment, but even so the flows into state and privatised firms remain surprisingly large ${ }^{20}$. The bulk of flows out of unemployment to jobs are in fact to the latter. How much does this tell us about the efficiency of the matching process ? Several points should be made at this stage. First, the numbers on the stock of unemployed are biased downwards as we are using registrations numbers. Second, information on vacancies largely relates to 'formal' sector jobs and hence refers mainly to the state and privatised firm sector. Third, while we are exploring the interaction between outflows from unemployment and the lagged stock of unemployed and vacancies, this obviously provides a somewhat dubious measure of efficiency. Why? Because we know that the bulk of Russian firms entered transition with large labor hoarding, the contraction of which has proceeded only gradually. In Section 1 we have already indicated that part of the slow run down in employment can be attributed to the association between firm size, as measured by employment, and subsidies received fromh government and/or the financial system. One result has not only been the restraint on involuntary separations and ultimately on inflows to unemployment but also the relatively high hiring rates reported by state firms. In other words, much of the hiring from unemployment is likely to be accounted for by state or privatised firms and, hence,

\footnotetext{
${ }^{17}$ Calculated as; Mismatch $=0.5 \sum N i / N(|(v i-u i)-(v-u)|)$ where u=unemployment rate; v-vacancy rate; ui=unemployment rate in region $\mathrm{I}$; vi=vacancy rate in region $\mathrm{I}, \mathrm{N}=$ total labor force and $\mathrm{Ni}=$ region labor force. ${ }^{18}$ See Coricelli, Hagemejer and Rybinski (1994)

${ }^{19}$ As to the reliabiliv of vacancies data, we suspect this to be less of a problem in Russia than in most OECD settings, partly because of the inertia of previous practices -- including the requirement on firms to post vacancies - and the relatively limited development as yet of an autonomous private sector.

${ }^{20}$ Yemtsov (1994).
} 
may in effect be for the 'wrong' reasons. This has obvious implications for how we interpret the matching function results. Constant returns, with the implication of a constant rate of growth of unemployment consistent with balanced growth, would hardly be an appropriate characterisation for a setting where labor hoarding was large. Rather, decreasing returns in matching could be interpreted as a desirable 'inefficiency', signalling, perhaps, an end to the dynamic labor hoarding apparently characteristic of the Russian state (now privatised) firm sector. Given the relatively early stage of transition, we might further expect a less than proportional association between unemployment stocks and outflows.

We now present the results from estimating an aggregate matching function, first proceeding with the general form with a Cobb-Douglas specification, viz; $O_{u}=A_{t i} U_{u}{ }^{\alpha} V_{t h}^{\beta}$, where $\mathrm{O}=$ outflows from unemployment in ith region; $U=$ stock of unemployed and $V=$ stock of vacancies. No 'technological progress' would give a constant multiplier over time. Taking logs the standard estimating equation becomes; $\ln \left(O_{i t}\right)=\ln \left(A_{i t}\right)+\alpha \cdot \ln \left(U_{i, t-1}\right)+\beta \cdot \ln \left(V_{i, t-1}\right)+\varepsilon_{i t}$

Our data cover the period January 1992 to April 1994 for all 79 administrative regions. Introducing a one period lag for the right hand side variables gives us a reference of 27 periods and 2133 observations. For efficient estimation, exploiting both cross section and time series components, we pool the data and allow for heterogeneity across region and time.

Assuming that the stock of registered unemployed represents a constant sample of the true unemployed' and that vacancies accurately represent job openings in the 'formal' sector, we are in effect attempting to measure the 'efficiency' of matching in one -- albeit very large -- segment of the labor market. Clearly, as indicated above, this is a 'conditional' efficiency. But given the size of the autonomous private sector, this is informative.

The results are presented in Table 11 for a pooled OLS estimate. Time dummies are introduced in both estimations. The coefficients are positively signed, their size is rather stable with or without time dummies, and are highly significant. Introducing a period dummy to capture a distinct phase from March through September 1993 when unemployment was falling did not affect the size of the estimated coefficients nor their significance. The size of the vacancies term is quite large and suggests that, compared with these results reported in Boeri (1994) for a range of Eastern European countries, 
there is a relatively strong effect of vacancies on outtlows to jobs. The size of the coefficient on the lagged unemployment term is also reasonably large. Even so, the matching function exhibits decreasing returns to scale ${ }^{21}$, indicating that a doubling of unemployment and vacancies, say, would be associated with a less than proportional change to outflows. Decreasing returns could be attributed in part to the lack of development of the labor market, institiutional inefficiencies as well as congestion effects. The inclusion of time dummies in principle allows us to capture the efficiency of matching over time. The coefficients decrease over time likely indicating the deterioration in the efficiency of matching.

Table 11: Matching function for 79 regions of Russia

Procedure: OLS pooled estimates with Time Dummies;

Dependent Variable: Log Outflows

Variable

Coefficient

T-stat

$\log U_{t-1}$

0.516

32.04

$\log V_{t-1}$

0.337

24.96

Constant

$-1.016$

$-7.48$

$\mathrm{R}^{2}=.63 ; \mathrm{s} . \mathrm{e}=.548 ; \mathrm{F}$ stat $=28.71$

We also estimated the same basic equation with monthly dummies. The coefficients remain very similar in size and significance. Further examining the coefficients on the time dummies, we observe relatively small variation across months, indicating little seasonal movement in the outflows to jobs. There is no clear change in the size of these coefficients over time. We also explored these relationships for a smaller sample of oblasts, restricting our attention to European Russia, some 39 oblasts, where a significant proprtion of Russian industrial activity is concentrated. Here, the coefficient on the vacancies term is notably smaller $-0.2-$ than for the full sample, but the general fit of the estimation is clearly superior. Again, we pick up no clear trend in the size of the time dummies.

How can these results be interpreted ? Clearly, the particularities of the Russian transition are important. In the absence of subsidies and other supports, firms are faced with the need to reduce labor hoarding. They have shyed away from these decisions, but over time as financing options have

21 Applying a $F$ test we reject the hypothesis that the lagged explanatory variables sum to unity and hence that constant returns obtains. 
narrowed and the reforms appear irreversible, decreasing returns in the formal job market are what we should expect, given initial conditions and the path of adjustment in aggregate and regional employments. The interaction between vacancies in the cconomy as a whole and the flows out of unemployment are very inexactly captured. But on the assumption that registered unemployment is a stable share of true unemployment, the evidence of decreasing returns suggests that the stock of unemployed as yet exerts an attenuated influence on hiring decisions and hence of outflows to jobs. Part of the reason is clear; flows to jobs outside the formal sector often bypass unemployment, while the formal sector's labor demand has tended to decline over time, as subsidies and other supports have been eroded. The effect of vacancies on flows to jobs can probably be traced to regional mismatch in the distribution of unernployed and vacancies.

Further inspection of individual region estimations points to a reasonably common response of outflows to unemployment but far less so for vacancies. Starting from the hypothesis that relatively thick regional markets are far more likely to experience constant or increasing returns, we might expect this to show up for major urban centers - like Moscow and St. Petersburg - which we know to have experienced relatively large flows. And indeed while the size of the lagged unemployment term is large in the case of Moscow, the vacancies term is negatively signed and this is also true for St. Petersburg. This contrasts with the estimations for the neighbouring Moscow and Leningrad oblasts. The fact that an increase in posted vacancies appears to be associated with a fall in the outflow to jobs likely points to an underlying problem of skill mismatch. In Moscow, for example, most posted vacancies are for manual and primarily male jobs; a significant share of the unemployed are educated women. Similar features can be detected for a number of the major industrial regions . including Nizhegorodskaia Krasnoiarskii krai and Samaraskaia oblast - with a negative association between vacancies and outflows. In the case of the larger urban centers, this component of mismatch can be traced to the manner in which Russian industrial firms have initially tended to shed clen :al and professional staff with most of the flows in to firms accounted for by manual or production we:kers ${ }^{22}$. However, in these industrial regions where the vacancies sign is perverse, this can partly be explained by the very low unemployment rate in the oblast associated with strong labor hoarding on the part of industrial firms, as well as the structure of output in these locations.

\footnotetext{
${ }^{22}$ This is well documented; sce, for instance, Commander and Yemtsov (1994)
} 


\section{Conclusion}

Russian unemployment has proven rather elusive, including in statistical terms. But one thing is clcar; the unemployed are significantly in excess of those registered at the Employment Offices. Yet strangely, while the latter series shows a clear upward trend -- with registered unemployment now above 2 percent - more inclusive, survey-based measures show rather little trend since early 1992. In other words, unemployment seems to have ranged between 5-6 percent: indicating, amongst other things, the size of the unemployment inherited from the Soviet period.

We report the findings of a survey of the unemployed and short time workers for 1994q1 which gives a true rate of no more than 5.4 percent. Assuming that those on extreme short time are almost equivalent to the unemployed, the immediate employment overhang amounts to not much more than 2 percent of the labor force. That number becomes much larger, of course, if we include all workers facing hours adjustment. But this is not appropriate, in part because many actually face quite limited contraction in working time. The survey results also indicate that for those who experience a spell in unemployment, durations have remained low with relatively high exit to job probabilities.

In short, even if we accept that the official statistics overstate output and employment losses by simply not capturing the growth in the private sector, the contraction in net employment has been small . Russia clearly does not correspond to the general East European experience in which employment losses in the state sector became large relatively quickly.

But despite the gradual increase, there are clear signs that unemployment is rising and set to rise further. The initial composition of the unemployed -- with its huge bias toward women -has now disappeared and the incidence seems more widely spread. Further, there is significant regional dispersion, with some of the more adversely affected regions having unemployment rates significantly in excess of 10 percent. Labor mobility is absent and, despite signs of wage flexibility and an emerging, conventional association at regional level between changes to wages and unemployment, it seems likely that regional variation will be long lasting, in part because of large spatial mismatch in the distribution of the unemployed and jobs. We write down a simple model designed to capture changes in relative region employment and wages. We indicate a number of 
channels by which relative employment and unemployment are likely to display a trend with persistence.

Finally, our matching functions indicate a decreasing 'efficiency' in matching over time. The coefficient on the vacancies term in the pooled estimation is larger than that estimated for several Eastern European economies but there appears to be quite large variance over individual regions. Aside from hinting at the problem of skill mismatch in some of labor markets, the fact that returns are decreasing over time likely picks up the changing behavior by firms with respect to employment. This is evidently related to changes in firm sector access to subsidies and other financing options. The obvious upward shift in unemployment that results is likely to have rather different regional consequences.

\section{References}

Blanchard, Olivier and Lawrence Katz, 1992. Regional Evolutions, Brookings Papers on Economic Activity, Washington DC

Boeri, Tito, 1994, Unemployment Dynamics and Labor Market Policies, in Commander and Coricelli

Commander, Simon and Fabrizio Coricelli, (eds), 1994. Unemployment and Restructuring in East Europe and Russia. World Bank, Washington DC, (November, forthcoming)

Commander, Simon, John McHale and Ruslan Yemtsov, 1994. Russia, in Commander and Coricelli

Commander, Simon and Ruslan Yemtsov, 1994. Privatization in Russia; Does it Matter ? Some Early Evidence on the Behavior of Privatized and Private Firms. World Bank, mimeo, January 1994

Coricelli, F, K. Hagemejer and K. Rybinski, 1994. Poland, in Commander and Coricelli

Yemtsov, Ruslan, 1994. Ingoing and outgoing flows in employment. Paper presented at IIASA Conference on 'Restructuring and the recovery of output in Russia', Laxenburg, Austria, 9-11 June, mimeo. 


\section{Appendix !}

\section{A model of region wage and employment setting}

We can now write down a simple model which tries to capture the relative region effects of shocks. Throughout, relative wages and employment are respectively given as;

$w_{r t}=\ln \left[\frac{W_{n}}{W_{t}}\right]$ where, $W_{n}$ is the wage in region $r$ at time $t$ and $W_{t}$ is the mean wage in the economy at time $t$. The relative wage gives the deviation of the wage in the particult region from the average wage for the economy as a whole. It will be positive $\left(w_{n}>0\right)$ when the wage in the region is greater than average level $\left(W_{n}>W_{t}\right)$ and negative when $\left(w_{n}<0\right)$.

$n_{n}=\ln \left[\frac{N_{n} / L F_{n}}{N_{f} / L F_{t}}\right]$ where, $\mathrm{N}_{n} / L F_{n}$ is employment in region $\mathrm{r}$ at time $\mathrm{t}$, and $\mathrm{N}_{\mathrm{t}} / L F_{t}$ is mean employment in the economy at time $t$.

The relationship between relative employment and relative unemployment is given by;

$n_{n}=\ln \left[\frac{1-U_{n} / L F_{n}}{1-U_{t} / L F_{t}}\right] \approx-\left[\frac{U_{n}}{L F_{n}}-\frac{U_{1}}{L F_{t}}\right]=-u_{n}$

At the level of each region, labor demand has a constant inverse elasticity $d_{r}$ and can be written as; $W_{n}=C_{n} \cdot\left(N_{n} / I F_{n}\right)^{-d_{r}}$

where $\mathrm{C}_{n}$ is a constant. The same relation can be generalized to the economy as whole. This means that the relative wage, $w_{n}$, for region $r$ is;

$w_{n}=\ln \left[\frac{W_{n}}{W_{t}}\right]=\ln \left[\frac{C_{n}}{C_{t}} \cdot\left(N_{t} / L F_{t}\right)^{d-d_{r}} \cdot\left(\frac{N_{n} / L F_{n}}{N_{t} / L F_{t}}\right)^{-d_{r}}\right]$

It can be restated more simply as

$w_{n}=q_{n}-d_{r} \cdot n_{n}$

where $q_{n}$ gives the position of the relative labor demand curve, so that,

$q_{n}=\ln \left[\frac{C_{n t}}{C_{t}} \cdot\left(N_{t} / L F_{t}\right)^{d-d_{r}}\right]=\ln \left[\frac{C_{n}}{C_{t}}\right]+\left(d-d_{r}\right) \cdot \ln \left[N_{t} / L F_{t}\right]$

$\mathrm{q}_{\mathrm{r}}$ is positive when the region has a higher relative labor productivity and higher relative elasticity of labor demand. As such, the relative labor demand curve does not express relationship between 
wage and employment; it is expressed in terms of deviations of wages and employment from average levels. Movements in this curve do not give changes in labor demand in the region but the relative size of such changes as compared to the average level.

Similarly, the relative labor supply function can be written as;

$w_{r}=v_{r}+s_{r} \cdot n_{r}$

where $v_{n}$ gives the position of the relative labor supply curve, so that,

$V_{r t}=\ln \left[\frac{D_{r t}}{D_{t}} \cdot\left(N_{t} / L F_{1}\right)^{s-s}\right]=\ln \left[\frac{D_{r t}}{D_{t}}\right]-\left(s-s_{r}\right) \cdot \ln \left[N_{1} / L F_{t}\right]$

where $D_{r}$ is the marginal disutility of labor in a region.

Solving this system of relative labor demand and labor supply equations we get;

$n_{n}^{\text {eq }}=\frac{q_{n}-v_{n}}{d_{r}+s_{r}} ; w_{n}^{e q}=\frac{s_{r} \cdot q_{n}+d_{r} \cdot v_{n}}{d_{r}+s_{r}}$

We can introduce a disequilibrium term, a parameter $\mu_{r}$, which summarizes a range of possible factors, such as wage setting policies that are not region-specific, that might, by introducing rigidities result in departures from equilibrium wages and employment so that;

$w_{n}=w_{n}^{\text {eq }} \cdot\left(1-\mu_{r}\right) ; n_{r}=n_{r}^{e q} \cdot\left(1+d_{r}^{-1} \cdot \mu_{r}\right)$

We now consider the likely effect of shocks to relative employment and wages arising from two possible sources; a shock to relative labor demand and a shock to relative labor supply. In this context, a shock to labor supply will not come about through migration, but may be important given the initial conditions. We know that Russian participation rates were high and that, combined with demographics, may imply non-trivial labor supply effects in the transition. Thus, shocks to labor demand (which we assume however will dominate) and labor supply will result in shifting the parameters, $q_{r}$ and $v_{r}$,

$q_{n+1}-q_{n} \equiv x_{r} ; v_{n+1}-v_{n} \equiv-\varepsilon_{r}$

where $x_{r}$ summarizes changes in demand for a region's goods and $\varepsilon_{r}$ summarizes changes in labor supply.

These shocks lead to changes in relative employment and wages;

$n_{n+1}-n_{r}=\frac{x_{r}+\varepsilon_{r}}{d_{r}+s_{r}} \cdot\left(1+d_{r}^{-1} \cdot \mu_{r}\right) ; \quad w_{r+1}-w_{n}=\frac{s_{r} \cdot x_{r}-d_{r} \cdot \varepsilon_{r}}{d_{r}+s_{r}} \cdot\left(1-\mu_{r}\right)$ 
Using these equations we can relate changes in relative employment and relative wages;

$n_{n+1}-n_{n}=\gamma_{r}^{-1} \cdot\left(w_{n+1}-w_{n}\right)$

where,

$\gamma_{r}=\left(s_{r} \cdot \frac{x_{r}}{x_{r}+\varepsilon_{r}}-d_{r} \cdot \frac{\varepsilon_{r}}{x_{r}+\varepsilon_{r}}\right) \cdot \frac{1-\mu_{r}}{1+d_{r}^{-1} \cdot \mu_{r}}$

We now need consider the evolution of relative wages and employment given shocks. As indicated earlier, this will be sensitive to the way in which regions interact with each other. We can think of this in terms of at least three channels. They can be represented in terms of the ability to trade goods and services across regions; the ability to move capital across regions and, finally, the ability of labor to move across regions. For our purposes, the main assumption is that mobility or workers and hence of migration is absent. By contrast, we assume that capital can move across regions and will do so. It seems reasonable to believe that low relative wages in a region $\left(W_{n}<W_{t}\right)$ or $W_{n}<0$ will eventually sponsor job creation in that region and, in due course, will lead to an increase in relative employment ${ }^{23}$.

This implies that the growth rate of employment is proportional to the relative wage;

$n_{n+1}-n_{n}=-\alpha \cdot w_{n}$

or

-

$n_{n}=-\alpha \cdot w_{n}$

in continuous time. The parameter $\alpha$ summarizes the degree to which capital is mobile.

Substituting changes in the wage for changes in employment, we can also get an expression for determining the adjustment over time of the relative wage;

$\dot{w}_{n}=-\tau_{w}^{-1} \cdot w_{n}$

which gives in continuous time, $w_{n}=w_{r 0} \cdot e^{-\frac{1}{\tau_{m}}}$

or in discrete time,

$w_{n}=w_{r 0} \cdot\left(1-\tau_{w}^{-1}\right)^{t}$

\footnotetext{
${ }^{23}$ Note that we could easily rewrite the above in terms of relative unemployment given shocks. Further, we could assume that wages were negatively related to unemployment at regional level, so that combining the relationship between relative wages, employment and unemployment, we get: $\dot{w}_{n}=-\gamma_{r} \cdot \dot{u}_{n}$
} 
Clearly, relative employment will have the same time path as relative wages and also will tend to zero when $t$ tends to infinity ${ }^{24}$.

We can now see that the parameter $\tau_{w}$ in the time path of relative wages and employment characterizes the approximate time for the adjustment process and can be expressed through the main parameters of our model.

$$
\tau_{w}^{-1}=\alpha \cdot \gamma_{r}=\alpha \cdot\left(s_{r} \cdot \frac{x_{r}}{x_{r}+\varepsilon_{r}}-d_{r} \cdot \frac{\varepsilon_{r}}{x_{r}+\varepsilon_{r}}\right) \cdot \frac{1-\mu_{r}}{1+d_{r}^{-1} \cdot \mu_{r}}
$$

It is inversely proportional to the incentive to create new jobs $(\alpha)$ and is proportional to the elasticity of labor supply in the case of labor demand shock $\left(\varepsilon_{\mathrm{r}}=0\right)$ or to the elasticity of labor demand in the case of labor supply shock $\left(x_{r}=0\right)$. In the general case it is proportional to the weighted elasticity.

From the above, we can see that impact of shocks will depend on the relative weight of labor demand as against labor supply shocks and their relative elasticities. How long lasting these shocks are will also depend on the job creation parameter, and hence implicitly on the mobility of capital. In so far as job creation is driven by the movement in the relative wage, the presence of wage rigidities will be important.

In our model, we can easily see that such rigidities might enter through two immediate channels. The simplest type of relative wage rigidity arises through the distribution of relative wages over all regions. As it follows from the time path of $w_{n}$, there is inertia in relative wages. Regions with high (low) relative wage will tend to keep their wage above (below) the average level over the adjustment. A second possible source could be through the actions of local governments, which we crudely characterize by the parameter $\mu_{r}$. This might take the form of intervention in region-specific wage setting, as, say, through maintenance of earlier wage relativities. A third type of relative wage rigidity concerns the nonzero equilibrium distribution of relative wages $w_{\text {rec }}$ and may be introduced with the help of the following equation $\dot{w}_{r r}=-\tau_{w}^{-1} \cdot\left(w_{r t}-w_{r o t}\right)$.

\footnotetext{
${ }^{24}$ It is the case only if the parameter $\tau_{w}$ is strictly positive. But in some cases it can become negative and instead of convergence of regional wages to the average level we can have departures from that level.
} 
Title

WPS1411 Income Inequality. Wellare, and Poverty: An Illustration Using Ukrainian Data

WPS1412 Foreign Technology Imports and Economic Growth in Developing Countries

WPS1413 Endogenous Distortions in Product and Labor Markets

WPS1414 The World Bank and Legal Technical Assistance: Initial Lessons

WPS1415 China's GDP in U.S. Dollars Based on Purchasing Power Parity

WPS1416 Informal Regulation of Industrial Pollution in Developing Countries: Evidence from Indonesia

WPS1417 Uncertainty and Global Warming: An Option-Pricing Approach to Policy

WPS1418 The Impact of Labor Market Regulations

WPS1419 Industry Structure and Regulation

WPS1420 Legislative Frameworks Used to Foster Petroleum Development

WPS1421 Distribution of Income and the Income Zeljko Bogetic Tax Burden in Bulgaria

WPS1422 Efficiency in Bulgaria's Schools: A Nonparametric Study

WPS1423 The Role of Commercial Banks in Enterprise Restructuring in Central and Eastern Europe

WPS1424 Terms-ol-Trade Shocks and Optimal Luis Serven Investment: Another Look at the Laursen-Metzler Effect Fareed M. A. Hassan

Zeljko Bogetic Sajal Chattophadyay

Contact

for paper

Xiaoming Zhang

Heng-lu Zou

January 1995

C. Jones

37754

Martin Rama

Guido Tabellini

The World Bank

Legal Department

Ren Ruoen

Chen Kai

Sheoli Pargal

David Wheeler

Andrea Baranzini

Marc Chesney

Jacques Morisset

Lyn Squire

Sethaput Suthiwart-

Narueput

Martin C. Stewart-Smith

February 1995

N. James

82758

February 1995

W. Onorato 81611

February 1995

F. Smith 36072

February 1995

F. Smith 36072

Millard Long

Izabela Rutkowska

February 1995

A. Gamer 37670

February 1995
E. Khine 37471 


\section{Pollcy Aesearch Working Paper Series}

$\begin{array}{clll}\text { Title } & \text { Author } & \text { Date } & \begin{array}{l}\text { Contect } \\ \text { for paper }\end{array} \\ \begin{array}{l}\text { WPS1425 On the Intersectoral Migration of } \\ \text { Agricultural Labor }\end{array} & \begin{array}{l}\text { Donald Larson } \\ \text { Yair Mundlak }\end{array} & \text { February } 1995 & \begin{array}{l}\text { J. Jacobson } \\ 33710\end{array} \\ \begin{array}{l}\text { WPS1426 Russian Unemployment: Its } \\ \text { Magnitude, Characteristics, and } \\ \text { Regional Dimensions }\end{array} & \begin{array}{l}\text { Simon Commander } \\ \text { Rusian Yemtsov }\end{array} & \text { February } 1995 & \text { V. Reid } \\ & & & 35195\end{array}$

